\title{
On the influence of the proportion of PEO in thermally controlled phase segregation of copoly(ether-imide)s for gas separation.
}

\author{
AlbertoTena $^{1}$, Angel Marcos-Fernández ${ }^{1,2}$, Laura Palacio ${ }^{1}$, Pedro Prádanos ${ }^{1}$, \\ Angel E. Lozano ${ }^{1,2}$, Javier de Abajo ${ }^{1,2}$ and Antonio Hernández ${ }^{1}$ \\ ${ }^{1}$ Smap UA-UVA-CSIC, Universidad de Valladolid, Facultad de Ciencias, Real de \\ Burgos s/n, 47071 Valladolid, Spain \\ ${ }^{2}$ Instituto de Ciencia y Tecnología de Polímeros, CSIC, Juan de la Cierva 3, 28006 \\ Madrid, Spain
}

\section{Summary}

A complete series of aliphatic aromatic copoly(etherimide)s, based on an aromatic dianhydride (BPDA), an aromatic diamine (ODA) and a diamino terminated poly(ethylene oxide) (PEO2000) of $2000 \mathrm{~g} / \mathrm{mol}$ molecular weight, using different PEO contents, has been synthesized. Cast films of these copolymers have been thermally treated and characterized by FTIR-ATR, DSC, TGA and SAXS. It has been found that there is a direct relationship between phase segregation and permeability for increasing treatment temperatures.

Results show that permeability is higher when PEO content increases in the copolymer. Selectivity for $\mathrm{O}_{2} / \mathrm{N}_{2}$ and $\mathrm{CO}_{2} / \mathrm{CH}_{4}$ gas pairs follows the same tendency, while those for $\mathrm{CO}_{2} / \mathrm{N}_{2}$, and $\mathrm{CH}_{4} / \mathrm{N}_{2}$ give higher selectivities for intermediate (30-40 \%) PEO contents. Especially promising are the results for these two pairs of gases because materials with high permeability with high selectivity can be obtained.

The Maxwell model has been applied to predict permeability (for $\mathrm{CO}_{2}, \mathrm{CH}_{4}, \mathrm{O}_{2}$ and $\mathrm{N}_{2}$ ) from known data for pure BPDA-ODA and neat PEO and it has been found that assuming PEO as the dispersed phase, the use of this equation is adequate for percentages up to approximately a $40 \%$ over which we should assume that it is the aromatic part of the copolymer which plays the role of dispersed phase.

Keywords: Copoly(ether-imide) membrane; SAXS; Phase segregation; Thermal treatment; Gas separation; Maxwell equation; Proportion; PEO; BPDA-ODA; carbon dioxide $\left(\mathrm{CO}_{2}\right)$

*membrana@termo.uva.es 


\section{Introduction}

Nowadays, the role of polymeric membranes applied to gas separation is more and more important. Although some of them have already an application in industrial separations[1], the truth is that a lot of research is still necessary to discover new materials and/or to improve the properties of existing polymers to assure them an actual applicability at industrial level.

It is obvious that separations where $\mathrm{CO}_{2}$ is involved are of great interest now. There are several sources (power plants, steel, cement production plants or the chemical industry) where important amounts of $\mathrm{CO}_{2}$ are generated, and it is therefore necessary to develop new technologies to curb as far as possible the greenhouse effect. Specifically, one of the most demanding applications is the separation $\mathrm{CO}_{2} / \mathrm{N}_{2}$. In all cases, in order to guarantee a real application of a new polymeric material in gas separation, an adequate balance of high permeability and good selectivity must be achieved [2-3].

On the other hand, there is an urgent need to change the world's dependence on oil and to find an alternative energy source or to use cleaner fuels [4], and in this sense, natural gas appears as an attractive alternative due to its lower carbon footprint as compared with gasoline or coal, for example. Despite the increasing demand of natural gas, the gas reserves have remained reasonably stable because producers have been able to replace most of the drained reserves with new resources [5-6]. Nevertheless, a high percentage of natural gas reserves cannot be used because they are contaminated by nitrogen and thus they do not fit the required specifications for its transport and exploitation[7-9].

In order to be useful in such gas separation applications, a polymer film should show a preferential affinity for condensable gases such as $\mathrm{CO}_{2}$ or $\mathrm{CH}_{4}$ as compared with a mostly ideal gas such as $\mathrm{N}_{2}$. Moreover, in addition to the criteria of permeability and selectivity, membranes to be used in this type of separations, must give high flow and have good mechanical and thermal resistance. 
Glassy polymers and in particular polyimides are well known by their excellent thermal properties, along with an extraordinary ability to separate complex mixtures of gases in diverse applications [10-12]. Thus, among all the polymeric membranes, it has been widely demonstrated that the use of aromatic polyimides is one of the best alternatives.

Typically these materials have a high selectivity but with a not always sufficiently high permeability [13-14]. It is therefore necessary to increase the affinity of the compounds for condensable gases such as $\mathrm{CO}_{2}$, or $\mathrm{CH}_{4}$ and one of the most common approaches to meet these requirements is the use of block-copolymers.

Aromatic-aliphatic block-copolymers usually combine a hard block and a soft block. The hard block can be formed by a polymer with well-packed and highly rigid structures; as a result it forms the glassy segment of the polymer chain with usually low free volume. In contrast, the soft block can consist in a polymer with more flexible, low $\mathrm{T}_{\mathrm{g}}$, chains, which can form rubbery segments in the polymer chain normally with high free volume. Also, when aromatic-aliphatic block copolymers are phase-separated, their glassy polymer segments would provide mechanical support. The rubbery segments, due to the nature of the flexible chain structure, allow an efficient transport of gas, giving a good permeability to the copolymer [15-16].

It is known that poly(ethylene oxide) (PEO) compounds give excellent results for the $\mathrm{CO}_{2}$ separation from other light gases [17-18]. In the same way, this category of compounds having oxyethylene groups in the structure showed good permeability for the couple $\mathrm{CH}_{4} / \mathrm{N}_{2}$ [19]. In view of this, the use of these compounds, block-copolymers by combination of aromatic and PEO polyimides, appears to be a successful route[2022].

These compounds have also good permselectivity for the couples $\mathrm{CO}_{2} / \mathrm{N}_{2}$ and $\mathrm{CH}_{4} / \mathrm{N}_{2}$. This was attributed mainly to the high solubility-selectivity[19], which could be due to the existence of strong interactions of $\mathrm{CO}_{2}$ with the oxyethylene group in PEO. The interaction between $\mathrm{CO}_{2}$ and PEO has been discussed and used for the development of $\mathrm{CO}_{2}$ selective membranes previously[23-25]. However $\mathrm{CH}_{4} / \mathrm{N}_{2}$ separation has not been studied so intensively [26]. 
It is also necessary for the development of new materials to find a good balance between the hard and soft block segments in order to provide good separation without loss of permeability. For this reason, we propose here a complete study of the influence of composition on the properties of separation for a system where both the hard part, in this case the aromatic polyimide BPDA-ODA, and the soft one, an aromatic-aliphatic polyimide (BPDA-PEO2000) having poly(ethylene oxide) chains, remain unchanged.

The properties of such material have been analyzed by standard techniques of characterization (DSC, TGA, TMA, mechanical properties and density). Also, SAXS experiments were performed to study the segregation in the different phases of poly(ether-imide)s. Finally, we have modeled the copoly(ether-imide)s in order to predict their permeability to different gases by applying the Maxwell's equation.

\section{Experimental}

\subsection{Chemicals}

3,3',4,4'- biphenyltetracarboxylic dianhydride (BPDA), and 4,4'-oxydianiline (ODA) were purchased from Aldrich. These products were purified by sublimation at high vacuum just before being used. Polyoxyethylene bis(amine) (Jeffamine ED-2003, n= 41) with nominal molecular weight of $2000 \mathrm{~g} / \mathrm{mol}$, was kindly donated by Huntsman ${ }^{\circledR}$ (Holland). This polyether was dried at $70{ }^{\circ} \mathrm{C}$ in vacuum for 5 hours and stored in a desiccator at vacuum until use. Anhydrous N-methylpyrrolidinone (NMP), to be used as polymerization solvent, was purchased from Sigma-Aldrich Co. Figure 1 shows the chemical structure of the monomers.

$$
\text { Figure 1. Chemical structure of the monomers and reaction process. }
$$

\subsection{Synthesis of copoly(ether-imide)s}

The samples were synthesized by combination of the dianhydride (BPDA) with the aromatic diamine (ODA), and changing proportions of the aliphatic diamine (PEO). The 
corresponding copoly(ether-imide) will be designated by adding cPI to the w/w percentage of the aliphatic proportion. Thus, cPI-58 designates the sample BPDAPEO2000-ODA with a weight ratio between the aliphatic and aromatic diamines of $4: 1$ which corresponds to a mass proportion of PEO in the final copolymer of around $58 \%$.

Diamine-terminated poly(oxyethylene oxide) (PEO2000) ( $x$ mmol), and 4,4'oxydianiline (ODA) ( $y$ mmol) in weight ratios 1:4, 1:2, 1:1, 2:1, and 4:1 were dissolved in anhydrous NMP $(5 \mathrm{mmol}(\mathrm{x}+\mathrm{y}) / 10 \mathrm{~mL})$ in a $100 \mathrm{~mL}$ three-necked flask blanketed with nitrogen.

Then, the reaction mixture was cooled down to $0{ }^{\circ} \mathrm{C}$, and under mechanical stirring, a stoichiometric amount of BPDA dianhydride $(x+y \mathrm{mmol})$ was added and the mixture was stirred overnight at room temperature (see final resulting amounts in table 1). During this time the dianhydride completely dissolved and the solution reached high viscosity.

Table 1. Polymers synthesized in this work

\subsection{Preparation of the copolyimide dense films.}

The resultant viscous copolyamic acid solution was diluted with NMP to the appropriate viscosity for casting, filtered through a nominal \#1 fritted glass funnel, degassed, and cast onto a leveled glass plate. The resulting film was covered with a conical funnel to avoid fast evaporation of the solvent, dried at $80{ }^{\circ} \mathrm{C}$ overnight, and finally treated at different temperatures for 6 hours in a vacuum oven, in order to get a complete imidization (Table 1). Films of the copolymers of 50-70 $\mu \mathrm{m}$ in thickness were obtained. After that, thermal treatments under inert atmosphere were carried out at different temperatures. All films showed good mechanical properties.

\subsection{Characterization Methods}


Attenuated total internal reflectance-Fourier transform infrared analyses (ATR-FTIR)

A Thermal Analysis Q500 instrument was used for thermogravimetric analysis (TGA). Disc samples cut from films with weights between 5 and $15 \mathrm{mg}$ were tested. When running dynamic scans, it was done in Hi-Resolution mode, where the heating rate is automatically adjusted in response to changes in the rate of weight loss, which results in improved resolution, with an initial heating rate of $10{ }^{\circ} \mathrm{C} / \mathrm{min}$ under a flux of nitrogen.

Differential scanning calorimetry (DSC) analyses were carried out in a Mettler Toledo (DSC 822e) calorimeter equipped with a liquid nitrogen accessory. Disc samples cut from films weighting 5-15 mg were sealed in aluminium pans. Samples were heated with the following cyclic method in order to monitor the changes in thermal properties with thermal treatment: from $25{ }^{\circ} \mathrm{C}$, the sample was heated at $10{ }^{\circ} \mathrm{C} / \mathrm{min}$ to a target temperature; once reached, the sample was cooled at the maximum cooling rate accessible for the instrument to $-90{ }^{\circ} \mathrm{C}$, held at this temperature for $15 \mathrm{~min}$ and reheated at $10^{\circ} \mathrm{C} / \mathrm{min}$ to the next target temperature. The procedure was followed until the last treatment temperature was reached and a final run from $-90^{\circ} \mathrm{C}$ to $80^{\circ} \mathrm{C}$ was performed. In this way, in each heating run, the thermal properties for the copolymers after treatment to the previously reached temperature were obtained, and a plot of thermal properties versus "instantaneous" thermal treatment could be built.

The densities $(\rho)$ of the dense membrane films were determined using a CP225D Sartorius balance, provided with an immersion density kit.

SAXS measurements were performed at the beamline BM16 at the European Synchrotron Radiation Facility (Grenoble, France). Wavelength of the X-ray beam was $0.980 \AA$. Detector calibration was done with silver behenate $\left(\mathrm{AgC}_{22} \mathrm{H}_{43} \mathrm{O}_{2}\right)$, and the characteristic distance $\mathrm{L}$ was calculated from the scattering vector $(q=4 \pi(\sin \theta) / \lambda$, $\lambda=$ wave length, $2 \theta=$ scattering angle). Disc samples cut from films were placed in a Linkam hot stage and heated at $10{ }^{\circ} \mathrm{C} / \mathrm{min}$ while the SAXS spectra were recorded. Calibration of temperature gave a difference of approximately $7{ }^{\circ} \mathrm{C}$ between the temperature reading at the hot stage display and the real temperature at the sample. 
Thermomechanical (TMA) tests were performed in a Rheometric Scientific instrument model DMTA V. Rectangular test pieces of $3 \mathrm{~mm}$ width and $20 \mathrm{~mm}$ length were cut from films. A distance of $10 \mathrm{~mm}$ was set between fixation clamps. Runs were carried out from ambient temperature at $2{ }^{\circ} \mathrm{C} / \mathrm{min}$ with a static stress of $3 \mathrm{MPa}$.

The permeability, $\mathrm{P}$, for $\mathrm{O}_{2}, \mathrm{~N}_{2}, \mathrm{CO}_{2}$ and $\mathrm{CH}_{4}$ was determined by using a permeator with constant volume and variable pressure which uses the time-lag operation method. The measurements were carried out at 3 bar and $30^{\circ} \mathrm{C}$. A sketch of the device used has been shown elsewhere[27]. The strategy known as "time-lag" method, attributed to Daynes et al. [28], is very appropriate to determine permeability, diffusivity and indirectly solubility of a sample by a simple, rapid and accurate method working under transitory regime. The method has been successfully applied to polymer permeation by many authors [29-30]. Its theoretical framework, as well as the practical possibilities and limits of the time-lag technique have been abundantly documented [31]. It is nowadays an accepted method to assess the permeability and diffusion coefficients of a gas through a polymer film. Because permeability is a consequence of diffusivity and solubility, this magnitude can be evaluated as

$$
S=\frac{P}{D}
$$

In this way both $\mathrm{P}$ and $\mathrm{D}$ and, consequently $\mathrm{S}$, can be evaluated easily by this time-lag method.

\section{RESULTS AND DISCUSSION}

\subsection{Copoly(ether-imide)s imidization}

After the films were dried overnight, they were heated at different temperatures (see Table 1) to almost completely removal of the solvent, and infrared spectra were recorded to check for the progress of imidization. After this process, the polymer films resulted to be insoluble in DMAc (dimethylacetamide), NMP, Hexane, Toluene, THF (tetrahydrofuran) and $\mathrm{CH}_{2} \mathrm{Cl}_{2}$ (dichloromethane). 
Under the commented protocol, films with diamines ratio 4:1 and 2:1 (cPI-58 and cPI43) were almost completely imidized according to their FTIR spectra (within the detection limits of the FTIR technique) at $120^{\circ} \mathrm{C}$. For the sample with the ratio 1:1 (cPI29 ), the imidization temperature was increased to $160{ }^{\circ} \mathrm{C}$, and for the polymers with the ratio 1:2 and 1:4 (cPI-17 and cPI-9) complete imidization was reached for temperatures over $180{ }^{\circ} \mathrm{C}$. In figure 2, the FTIR spectra of copoly(ether-imide) cPI-43 and its corresponding poly(amic acid) precursor are shown.

Figure 2. FTIR spectra of cPI-43 before imidization $\left(80^{\circ} \mathrm{C}\right)$ and after the thermal treatment at different temperatures $\left(120,160\right.$ and $\left.200{ }^{\circ} \mathrm{C}\right)$.

For all synthesized copolymers, the bands centered around 3260, 1650, 1603 and 1538 $\mathrm{cm}^{-1}$ strongly decrease or disappear, and the bands at approximately 1774, 1712, 1370 and $738 \mathrm{~cm}^{-1}$ increase or appear with imidization. The spectrum (see Figure 2) for cPI43 show the differences between the samples with and without imidization, and the lack of differentiation for the samples treated at $120{ }^{\circ} \mathrm{C}, 160{ }^{\circ} \mathrm{C}$ and $200{ }^{\circ} \mathrm{C}$. This confirms that at a temperature of $120{ }^{\circ} \mathrm{C}$ imidization was completed for this copolymer as mentioned.

The full imidization temperature needed for the copolymers with higher polyether proportions is remarkably lower than that needed for fully aromatic polyimides [20-21]. For the copolymers with low PEO content, cPI-17 and cPI-9, the structure approaches that of a fully aromatic polyimide and higher temperatures are needed to complete the imidization.

\subsection{Thermal Stability}

Thermogravimetric analysis was performed to evaluate the thermal stability of the synthesized copolymers. Dynamic runs in High-Resolution mode, in a nitrogen atmosphere, for fully imidized copolymers (annealed at $120^{\circ} \mathrm{C}$ for 6 hours in the case of cPI-58 and cPI-43 copolymers, at $160{ }^{\circ} \mathrm{C}$ for 6 hours to cPI-29 and annealed at $180{ }^{\circ} \mathrm{C}$ for 6 hours in the case of copolymers cPI-17 and cPI-9) showed a weight loss pattern consisting of three consecutive steps (see figure 2): an initial loss from ambient 
temperature to $270-300{ }^{\circ} \mathrm{C}$; a second loss from $270-300{ }^{\circ} \mathrm{C}$ to $460-470{ }^{\circ} \mathrm{C}$; and a third loss from $460-470{ }^{\circ} \mathrm{C}$ to $800{ }^{\circ} \mathrm{C}$.

Figure 3. TGA curves in dynamic conditions for PEO based copolymers. From top to bottom: cPI-9 (treated at $180^{\circ} \mathrm{C}$ for 6 hours); cPI-17 (treated at $180{ }^{\circ} \mathrm{C}$ for 6 hours); cPI29 (treated at $160{ }^{\circ} \mathrm{C}$ for 6 hours); cPI-43 and cPI-58 (treated at $120^{\circ} \mathrm{C}$ for 6 hours).

The first loss can be attributed to the absorbed water plus the residual solvent trapped in the film. The weight change for this step is in the order of 2 to $2.5 \%$ [32]. The second loss stage, after correcting for the first one, agrees with the theoretical contribution of poly(ethylene oxide) bis(amine) entering the copolymer composition [33], within a 3\% error (see Table 2), and it is therefore assigned to the loss of polyether block sequences. The third and final stage of weight loss is due to the thermal decomposition of the remaining aromatic polyimide segments.

Table 2. Results obtained by TGA for the prepared copolymers. The residue of the BPDA-ODA homopolymer at $800^{\circ} \mathrm{C}$ is $64 \%$ [34].

TGA analysis confirmed that the polyether chains are much less thermally stable than the aromatic segments, as already found for another copoly(ether-imide)s based on poly(ethylene oxide) [19] and therefore a selective degradation of the polyether moiety can be performed in these copolymers.

The maximum weight loss rate happened between $360-400{ }^{\circ} \mathrm{C}$ for all copolymers, being this temperature higher when the amount of aliphatic diamine is lower. In the same way, the char residue at $800{ }^{\circ} \mathrm{C}$ is higher for the copolymers with more proportion of aromatic chains.

\subsection{Calorimetric Studies}

The samples were heated in a DSC instrument with a cyclic method in order to monitor the changes in thermal properties with thermal treatment [19]. All the copolymers showed only the $\mathrm{T}_{\mathrm{g}}$ and $\mathrm{T}_{\mathrm{m}}$ for the poly(ethylene oxide) segments, and no transition for 
the aromatic polyimide segments could be detected. No significant changes in the could be expected for a PEO chain of $2000 \mathrm{~g} / \mathrm{mol}$ with restricted movement at the chain ends. From this result it can be deduced that PEO segments are in a separated phase of relatively high purity at any PEO content in the copolymer. This phase separated structure will be unambiguously confirmed later by SAXS.

However, there were changes in the $\mathrm{T}_{\mathrm{m}}$ of the PEO segments in the copolymers, which increased with decreasing PEO percentages (with the exception of cPI-58 that shows the highest melting point) as shown in Figure 4 where $\mathrm{Tm}$ is plotted as a function of the treatment temperature (the temperature instantaneously reached by the DSC) for the copolymers studied. An increase in the temperature of treatment increases slightly $T_{m}$ for most of the copolymers.

The same trend is found in the melting enthalpy of PEO segments. If a value of 8.67 $\mathrm{kJ} / \mathrm{mol}$ is taken for the melting enthalpy of PEO [35], the amount of crystallized PEO, in the samples studied in this paper, appeared higher when the PEO contained in the copolymers is lower $(0.9,6.2,8.5$ and $8.7 \%$ for cPI-43, cPI-29, cPI-17 and cPI-9) except for cPI-58, which reached a maximum value of PEO crystallinity of around $12 \%$. For copolymer cPI-58, PEO content is high enough to produce a well separated phase of pure PEO, whereas for the rest of the copolymers, when PEO content decreases the length of the aromatic polyimide segments increases, augmenting the thermodynamical incompatibility of the segments, and therefore, giving a purer PEO phase. Anyway, the mixing of polyimide segments in the PEO phase is very limited as demonstrated by the similar $\mathrm{T}_{\mathrm{g}}$ of the amorphous part of the PEO phase for these copolymers. For all the copolymers, the amount of crystallizable PEO segments increases with the increase on the temperature of thermal treatment, showing that phase separation improves with thermal treatment. In addition, it is worth noting out that at the temperature of measurement of permeabilities and selectivities, $30{ }^{\circ} \mathrm{C}$, the PEO present in the copolymers would be melted and in amorphous state.

Figure 4. Melting temperatures as a function of the treatment temperature.

\subsection{Thermomechanical Analysis}


Thermomechanical analysis has been also carried out in order to detect the glass transition temperature of the aromatic polyimide hard segments, which were not detected by DSC. The criterion to determine the $T_{g}$ of the polyimide segments was the temperature when strain is 10 times that of the sample at $100{ }^{\circ} \mathrm{C}$ [33].

For all the copolymers, the $\mathrm{T}_{\mathrm{g}}$ of the aromatic polyimide is well above ambient temperature, although lower than the corresponding $\mathrm{T}_{\mathrm{g}}$ for the pure aromatic polyimide homopolymer, BPDA-ODA, due to the lower polymerization degree and, consequently, lower length of the aromatic polyimide segments in the copolymer as compared to the corresponding homopolymer and the possible inclusion of some polyether segments in the polyimide domains [33]. The values for the copolymers in this work are

$180.1^{\circ} \mathrm{C}$ for cPI- $43<203.1^{\circ} \mathrm{C}$ for cPI- $29<220.7$ for cPI- $17<231.6^{\circ} \mathrm{C}$ for cPI-9

For copolymer cPI-58, after PEO melting, the material was too soft to be measured.

The $T_{g}$ of the aromatic portion of the copolymer clearly increases when the PEO content decreases. All samples have the same aromatic polyimide, and the same aliphatic polyether, thus the differences can only be due to different lengths for the aromatic polyimide segments, longer at lower PEO content in the sample.

\subsection{Small Angle X-ray Scattering}

$\mathrm{X}$-ray scattering experiments were performed at a synchrotron radiation source in order to follow, in real-time conditions, the irreversible development of the phase separated structure in these copolymers ${ }^{[19,33]}$ caused by their thermal treatment.

As mentioned elsewhere $[19,33]$ it is possible to obtain, from the SAXS spectra, both the relative invariant and the characteristic length of the segregated phases, Q' and L, as shown, for example, in Figure 5. Note that, to eliminate the influence of the different film thicknesses and electronic density, the relative invariant [Q' $r=Q^{\prime}(T) / Q^{\prime}($ baseline at $\mathrm{T})]$ and length $\left[\mathrm{L}_{\mathrm{r}}=\mathrm{L}(\mathrm{T}) / \mathrm{L}(\right.$ baseline at $\left.\mathrm{T})\right]$ are shown in the Figure. These curves 
show that there is a clear increase of phase segregation in the temperature range from 170 to $300{ }^{\circ} \mathrm{C}$ (the increase is continued until the end of the test temperature range).

Figure 5. Evolution of $\mathrm{Q}_{\mathrm{r}}$ and $\mathrm{L}_{\mathrm{r}}$ as a function of the temperature of treatment for the copolymers studied.

From the results obtained for $\mathrm{L}$ we get an idea on the size scale of the phase separated morphology. In this case, the highest values are observed for sample cPI-9 (more than $20 \mathrm{~nm}$ ) followed by cPI-17 (around 17,5 nm) and the rest of the samples (L around 14 $\mathrm{nm})$. For the range of PEO content studied in this work, it seems that the size scale of the phase separated structure is similar for intermediate values (58\% to 29\%) whereas at lower values, L increases when PEO content decreases. Moreover, it seems clear that when the copolymers are treated at higher temperatures, the segregated domains are bigger.

\subsection{Density}

The densities $(\rho)$ of the dense membrane films were determined according to the equation:

$\rho=\rho_{0} \frac{W_{\text {air }}}{W_{\text {air }}-W_{\text {liq }}}$

where $\rho$ is the density of the film, $\mathrm{W}_{\text {air }}$ and $\mathrm{W}_{\text {liq }}$ are the weights of the film in the air and immersed in an auxiliary liquid (in these measurements, isooctane was used because this polymer is reported to be insoluble in isooctane[36]) and $\rho_{\mathrm{o}}$ is the density of the auxiliary liquid (isooctane).

The so measured density is always between the values of pure aromatic polyimide (BPDA-ODA, which is $1.39 \mathrm{~g} / \mathrm{ml}$ [14]), and the density value for the aliphatic diamine (which is $1,068 \mathrm{~g} / \mathrm{ml}$, data provided by Huntsman ${ }^{\circledR}$ ).:

$$
\begin{aligned}
& \text { BPDA-ODA }\left(1,39 \mathrm{~g} / \mathrm{cm}^{3}\right)>\operatorname{cPI}-9\left(1,33 \mathrm{~g} / \mathrm{cm}^{3}\right) \approx \mathrm{cPI}-17\left(1,34 \mathrm{~g} / \mathrm{cm}^{3}\right)>\mathrm{cPI}-29 \\
& \left(1,32 \mathrm{~g} / \mathrm{cm}^{3}\right)>\operatorname{cPI}-43\left(1,29 \mathrm{~g} / \mathrm{cm}^{3}\right)>\operatorname{cPI}-58\left(1,24 \mathrm{~g} / \mathrm{cm}^{3}\right)>\text { PEO }\left(1,07 \mathrm{~g} / \mathrm{cm}^{3}\right)
\end{aligned}
$$


Of course, as it should be expected, density decreases as the PEO content increases.

\subsection{Gas transport properties}

According to our previous results for other similar aliphatic-aromatic copoly(ether imide)s $[19,37]$, the copolymers prepared and studied here show an improvement in permeation properties, depending on the thermal treatment. Results show a direct correlation between: treatment temperature, phase segregation and permeation properties.

Figure 6 shows the permeability (for: $\mathrm{CO}_{2}, \mathrm{CH}_{4}, \mathrm{O}_{2}$ and $\mathrm{N}_{2}$ ) through the copolymer cPI29 (ratio w/w between diamines 1:1) (29\% of PEO content) as a function of thermal treatment. The trend is quite analogous for all the copolymers showing an enhancement of permeability with the thermal treatment.

Figure 6. Permeability versus treatment temperature for the copolymer cPI-29.

If these data are compared with the results obtained by SAXS, it is clear that the improvement in phase separation leads to better permeation properties. In general, the increase in permeability is much higher for the maximum treatment temperatures, when most of the remaining solvent is released and the improvement in the phase separation is higher.

A very significant and clear way of showing the level of gas separation performance obtained is the Robeson's plot [38-39]. In these representations, the distance to the limit can give an idea of the compromise between permeation and selectivity of the samples. Also, in these figures (for the different gas pairs) the values of permeability and selectivity for the homopolymer BPDA-ODA and for pure PEO are shown. The permeability and selectivity of a pure BPDA-ODA membrane have been measured by us because values found in literature are highly inconsistent[40]. In the case of the other homopolymer BPDA-PEO, the pure PEO permeability and selectivity have been used as taken from data published by Lin and Freeman[24]. Because the PEO chain is quite 
long, the BPDA-PEO permeation properties can be represented by those of pure PEO.

Figure 7. Robeson's plot for the $\mathrm{O}_{2} / \mathrm{N}_{2}$ gas pair. The cross figure corresponds to BPDAODA and the figure star to PEO.

Figure 8. Robeson's plot for the $\mathrm{CO}_{2} / \mathrm{N}_{2}$ gas pair. The cross figure corresponds to BPDA-ODA and the star figure to PEO.

Figure 9. Robeson's plot for the $\mathrm{CO}_{2} / \mathrm{CH}_{4}$ gas pair. The cross figure corresponds to BPDA-ODA and the star figure to PEO.

Figure 10. Robeson's plot for the $\mathrm{CH}_{4} / \mathrm{N}_{2}$ gas pair. The cross figure corresponds to BPDA-ODA and the star figure to PEO.

A good material would give permeabilities as close as possible to the values of PEO, especially when $\mathrm{CO}_{2}$ is involved due to the favorable interactions between PEO and carbon dioxide, while showing selectivities as close as possible to the purely aromatic polyimide. In the materials shown in this work, the treatment temperature and the percentage of PEO can be controlled and should allow the modulation of the permeability-selectivity balance.

For $\mathrm{O}_{2} / \mathrm{N}_{2}$ separations and $\mathrm{CO}_{2} / \mathrm{CH}_{4}$, as expected, permeability and selectivity are between those for the two homopolymers. Most of the cPIs, for the $\mathrm{CH}_{4} / \mathrm{N}_{2}$ and $\mathrm{CO}_{2} / \mathrm{N}_{2}$ gas pairs, show high selectivities that are even over those for BPDA-ODA and pure PEO (for these pairs the selectivity of PEO is over that of BPDA-ODA). The permeability increases always with the percentage of PEO in the sample. Thus, for these pairs, some cPIs with high percentages of PEO give both high permeability and selectivity that place them very close to the corresponding upper bound. It is worth noting here that for the $\mathrm{CH}_{4}$ and $\mathrm{N}_{2}$ pair, $\mathrm{CH}_{4}$ is more permeable than $\mathrm{N}_{2}$ giving an inverse selectivity (usually $\mathrm{N}_{2}$ is more permeable in glassy polymers) and no Robeson's limit has been yet proposed. In this case a tentative line was drawn by us on the basis of some of the most interesting inverse selectivity polymers [19]. 
Referring now to the results obtained for the $\mathrm{CO}_{2} / \mathrm{N}_{2}$ couple, we can say that in general this type of block-copolymer substantially improves the selectivity found for other types of compounds such as polyacetylenes, polyarylates, polycarbonates, polysulfones, aromatic polyimides or polyethylene oxide. Permeability is not extraordinarily high, although actually only totally rubbery polymers and some polyimides based on the 6FDA dianhydride give higher values but with have substantially lower selectivities [41].

In order to analyze in some detail the effect of the proportion of polyether in these block copolymers, permeability is shown as a function of the percentage of PEO in Figure 11. The values for $0 \%$ and $100 \%$ PEO are also shown.

\section{Figure 11. Permeability as a function of the percentage of PEO.}

In this Figure, it is possible to observe a sigmoidal trend between BPDA-ODA and pure PEO values. In effect, permeabilities are near that of the pure aromatic polyimide between $0 \%$ and $20 \%$ of PEO, while from $40 \%$ to $100 \%$ of PEO permeabilities tend to that of pure PEO. This could be also an indication of a change in the morphology of the copolymers between 17 and 29\% PEO content, as suggested by the analysis of the $\mathrm{L}$ values in the SAXS section.

Similarly, results on selectivity are shown in Figure 12 as a function of the PEO content. As pointed out above for permeability, the selectivity values of these polymers are intermediate between those of BPDA-ODA and PEO for the couples $\mathrm{CO}_{2} / \mathrm{CH}_{4}$ and $\mathrm{O}_{2} / \mathrm{N}_{2}$. In this case, as mentioned above, the selectivity for pure aromatic polyimide is higher than for pure PEO, what is not the case for the couples $\mathrm{CH}_{4} / \mathrm{N}_{2}$ and $\mathrm{CO}_{2} / \mathrm{N}_{2}$, where the differences in solubility probably play an important role. As already commented, for these gas pairs, the selectivity is sometimes higher than those of the homopolymers. Thus, although permeability increases with the percentage of PEO it does not mean necessarily that a better permselectivity compromise would be achieved.

Figure 12. Selectivity variation as a function of percent of PEO. 
Due to this especial behavior of selectivity, although cPI-43 is less permeable than cPI-

Figure 13. Selectivity distance from BPDA-ODA selectivity values as a function of the proportion of PEO.

Figure 13 shows the selectivity for the copolymers normalized to the value of the BPDA-ODA homopolymer (value 1 and solid line). The so normalized values for the pure PEO are also indicated (dashed lines). Now, it is clear that for $\mathrm{CH}_{4} / \mathrm{N}_{2}$ and $\mathrm{CO}_{2} / \mathrm{N}_{2}$ pairs, the selectivity of the copolymers with PEO percentages in the range from 30 to $40 \%$ gives the best results (even better than those for both pure aromatic polyimide, BPDA-ODA, or pure PEO). The rigidity of the structure formed, together with the effect of $\mathrm{CH}_{4}$ and $\mathrm{CH}_{4}$ condensability and the interaction with the oxygen of the polymer chain should be the cause of this atypical effect. In the case of the $\mathrm{CH}_{4} / \mathrm{N}_{2}$ couple the presence of big amounts of PEO clearly favors the permeation of $\mathrm{CH}_{4}$ giving inverse selectivities as it can be seen in Figures 10 and 12. In the case of the couple $\mathrm{CO}_{2} / \mathrm{CH}_{4}$, because both gases are similar in nature, the selectivity is lower than for the pure aromatic polyimide. Similarly, for $\mathrm{O}_{2} / \mathrm{N}_{2}$, where none of the gases has a specific interaction with PEO and the separation is mainly due to the different sizes of the molecules, selectivity is clearly lower than for the pure BPDA-ODA.

\section{8. $\quad$ Permeability modeling}

These copolyimides consisting in an aromatic polyimide part (hard segments) and aliphatic polyether one (soft PEO chains), and having the ability to be phase-segregated by thermal treatment, can be modeled as a system formed by a disperse phase embedded in a continuous matrix.

It has been demonstrated that for such systems, the permeability for the samples with different PEO percentages in the polymer may be predicted by the Maxwell equation as shown below [42]: 
$P_{e f f}=P_{C}\left[\frac{P_{D}+2 P_{C}-2 \phi_{D}\left(P_{C}-P_{D}\right)}{P_{D}+2 P_{C}+\phi_{D}\left(P_{C}-P_{D}\right)}\right]$

$\mathrm{P}_{\text {eff }}$ is the effective permeability, $\mathrm{P}_{\mathrm{C}}$ and $\mathrm{P}_{\mathrm{D}}$ are the permeability of the continuous and disperse phase, respectively, and $\phi_{\mathrm{D}}$ is the volume fraction of the dispersed phase in the block copolymer.

In this type of polymers, the continuous phase can be the aromatic or the aliphatic segments depending on the relative amount of them. For this reason, we are making two different predictions depending on which segment is taken as the continuous or the disperse phase.

Figure 14. Predicted values for $\mathrm{CO}_{2}$ (a) and $\mathrm{CH}_{4}$ (b) using Maxwell equation comparing with the experimental for the samples at maximum treatment temperature (at $275^{\circ} \mathrm{C}$ for cPI-9, cPI-17 and cPI-29, and $250^{\circ} \mathrm{C}$ for cPI-43 and cPI-58).

Figure 15. Predicted values for $\mathrm{O}_{2}$ (a) and $\mathrm{N}_{2}$ (b) using Maxwell equation comparing with the experimental for the samples at maximum treatment temperature (at $275^{\circ} \mathrm{C}$ for cPI-9, cPI-17 and cPI-29, and $250{ }^{\circ} \mathrm{C}$ for cPI-43 and cPI-58).

Figures 14 and 15 show the permeability predicted for the different gases. It is observed there that for low PEO percentages the model assuming that PEO is the disperse phase fits the experimental data. On the other hand, the model assuming that PEO is the continuous phase works better for high PEO content.

\section{Conclusions}

A series of copoly(ether-imide)s presenting good gas separation properties have been prepared. These copolymers have been synthesized by the reaction between an aromatic dianhydride (BPDA), an aromatic diamine (ODA) and a diamine terminated poly(ethylene oxide) having a molecular weight of $2000 \mathrm{~g} / \mathrm{mole}$ (PEO-2000), with different percentage of PEO. 
It has been proved that higher PEO contents need lower temperatures to carry out the

SAXS experiments confirmed the phase separated structure and demonstrated the improvement on the phase separation with the increase in the treatment temperature. This segregation increases the permeability observing that their values clearly depend on the composition. As expected, when the polyethylene oxide percentage is higher, the permeability increases. This is reasonable, considering that the permeability of the soft part is much higher than the permeability of the hard part.

With respect to selectivity, different behaviors have been found. When the two gases are of the same nature as it is the case of $\mathrm{O}_{2} / \mathrm{N}_{2}$ and $\mathrm{CO}_{2} / \mathrm{CH}_{4}$, selectivity follows a predictable trend going from that of the pure BPDA-ODA copolymer to that of neat PEO in a gradual way. In the case of the $\mathrm{CH}_{4} / \mathrm{N}_{2}$ and $\mathrm{CO}_{2} / \mathrm{N}_{2}$ couples, the highest selectivity has been found for a PEO content of 30-40\%. In these compositions, their selectivities are much better than both those of the pure aromatic polyimide and of the pure PEO

Especially interesting are the values found for the $\mathrm{CO}_{2} / \mathrm{N}_{2}$ pair, which show a selectivity-permeability balance that place these copolymers very close to the Robeson upper bound. Also, very high permeabilities with high selectivities are found for these copolymers when the $\mathrm{CH}_{4} / \mathrm{N}_{2}$ couple of gases is considered. It is interesting to note out that all the copolymers have reasonably good mechanical properties. 
Finally, we have compared the results obtained in this work with those calculated by using the Maxwell model for mixtures. For PEO content below 20\%, the behavior approaches to a system with a continuous aromatic polyimide phase, whereas for PEO contents above $40 \%$, it could be assumed that PEO is the continuous phase.

\section{Aknowledgements}

We are indebted to the Spanish Junta de Castilla León for financing this work through the GR-18 Excellence Group Action and to the Ministry of Science and Innovation in Spain for their economic support of this work (MAT2008-00619/MAT, MAT201020668/MAT, MAT2011-25513/MAT and CIT-420000-2009-32). We also acknowledge financial support from the programme Consolider Ingenio 2010 (project CSD-0050MULTICAT).

Authors thank the Spanish Ministry of Economy and Competitivity for the economical support to access beamline BM16 at the European Synchrotron Radiation Facility (ESRF) in Grenoble (France). We are grateful to Dr. Ana Labrador and Dr. François Fauth for their help at BM16 station at the ESRF. The help provided by Sara Rodriguez in measuring gas permeability and selectivity is greatly appreciated. A. Tena thanks CSIC for a predoctoral JAE fellowship.

[1] R.W. Baker, Future directions of membrane gas separation technology, Industrial and Engineering Chemistry Research, 41 (2002) 1393-1411.

[2] R. Bounaceur, N. Lape, D. Roizard, C. Vallieres, E. Favre, Membrane processes for post-combustion carbon dioxide capture: A parametric study, Energy, 31 (2006) 22202234.

[3] E. Favre, Carbon dioxide recovery from post-combustion processes: Can gas permeation membranes compete with absorption?, Journal of Membrane Science, 294 (2007) 50-59.

[4] S. Pacala, R. Socolow, Stabilization Wedges: Solving the Climate Problem for the Next 50 Years with Current Technologies, Science, 305 (2004) 968-972.

[5] R. Egging, F. Holz, S.A. Gabriel, The World Gas Model: A multi-period mixed complementarity model for the global natural gas market, Energy, 35 (2010) 40164029.

[6] B.T.W. Low, Yan; Chung, Tai-Shung;, Polymeric Membranes for Energy Applications, in, John Wiley \& Sons, 2002. 
[7] R.H.V. Hugman, E.H.; Springer, P.S., Chemical Composition of Discovered and Undiscovered Natural Gas in the U.S. Lower-48, in: Executive Summary, Tight Sands and Gas Processing Department, 1993.

[8] C. Tannehill, Nitrogen Removal Requirements for Natural Gas, Gas Research Institute Topical Report, in: Purvin \& Gertz, Gas Research Institute, 1999.

[9] C.C. Tannehill, C. Galvin, Business characteristics of the Natural Gas Conditioning Industry, in: Topical Report to GRI, 1993.

[10] M.T.K. Bessonov, M.M.; Kudryavtsev, V.V.; Laius, L.A., Polyimides: Thermally Stable Polymers, in, Consultants Bureau, New York, 1987.

[11] M.K.M. Ghosh, K.L., Polyimides: Fundamentals and Applications, in, Marcel Dekker, New York, 1996.

[12] D.S. Wilson, H.D.; Hergenrother, P.M., Polyimides, in, Blackie, Glasgow, 1990.

[13] D. Ayala, A.E. Lozano, J. De Abajo, C. García-Perez, J.G. De La Campa, K.V. Peinemann, B.D. Freeman, R. Prabhakar, Gas separation properties of aromatic polyimides, Journal of Membrane Science, 215 (2003) 61-73.

[14] K. Tanaka, H. Kita, K. Okamoto, A. Nakamura, Y. Kusuki, Gas permeability and permselectivity in polyimides based on 3,3',4,4'-biphenyltetracarboxylic dianhydride, Journal of Membrane Science, 47 (1989) 203-215.

[15] T.A. Barbari, W.J. Koros, D.R. Paul, Gas transport in polymers based on bisphenol-A, Journal of Polymer Science, Part B: Polymer Physics, 26 (1988) 709-727.

[16] Y. Li, M. Ding, J. Xu, Gas separation properties of aromatic polyetherimides from 1,4-bis(3,4-dicarboxyphenoxy)benzene dianhydride and 3,5-diaminobenzic acid or its esters, Journal of Applied Polymer Science, 63 (1997) 1-7.

[17] Y. Hirayama, Y. Kase, N. Tanihara, Y. Sumiyama, Y. Kusuki, K. Haraya, Permeation properties to $\mathrm{CO}_{2}$ and $\mathrm{N}_{2}$ of poly(ethylene oxide)-containing and crosslinked polymer films, Journal of Membrane Science, 160 (1999) 87-99.

[18] M. Kawakami, H. Iwanaga, Y. Hara, M. Iwamoto, S. Kagawa, Gas permeabilities of cellulose nitrate/poly(ethylene glycol) blends membranes, Journal of Applied Polymer Science, 27 (1982) 2387-2393.

[19] A. Tena, A. Marcos-Fernández, A.E. Lozano, J.G. de la Campa, J. de Abajo, L. Palacio, P. Prádanos, A. Hernández, Thermally treated copoly(ether-imide)s made from bpda and alifatic plus aromatic diamines. Gas separation properties with different aromatic diamimes, Journal of Membrane Science, 387-388 (2012) 54-65.

[20] K.I. Okamoto, M. Fujii, S. Okamyo, H. Suzuki, K. Tanaka, H. Kita, Gas permeation properties of poly(ether imide) segmented copolymers, Macromolecules, 28 (1995) 6950-6956.

[21] K.I. Okamoto, N. Umeo, S. Okamyo, K. Tanaka, H. Kita, Selective permeation of carbon dioxide over nitrogen through polyethyleneoxide-containing polyimide membranes, Chemistry Letters 5(1993) 225-228.

[22] H. Suzuki, K. Tanaka, H. Kita, K.I. Okamoto, H. Hoshino, T. Yoshinaga, Y. Kusuki, Preparation of composite hollow fiber membranes of poly(ethylene oxide)containing polyimide and their $\mathrm{CO}_{2} / \mathrm{N}_{2}$ separation properties, Journal of Membrane Science, 146 (1998) 31-37.

[23] A. Car, C. Stropnik, W. Yave, K.V. Peinemann, Pebax $® /$ polyethylene glycol blend thin film composite membranes for $\mathrm{CO}_{2}$ separation: Performance with mixed gases, Separation and Purification Technology, 62 (2008) 110-117.

[24] H. Lin, B.D. Freeman, Gas solubility, diffusivity and permeability in poly(ethylene oxide), Journal of Membrane Science, 239 (2004) 105-117. 
[25] S.R. Reijerkerk, M.H. Knoef, K. Nijmeijer, M. Wessling, Poly(ethylene glycol)

[26] K.A. Lokhandwala, I. Pinnau, Z.J. He, K.D. Amo, A.R. DaCosta, J.G. Wijmans, R.W. Baker, Membrane separation of nitrogen from natural gas: A case study from membrane synthesis to commercial deployment, Journal of Membrane Science, 346 (2010) 270-279.

[27] J. Marchese, M. Anson, N.A. Ochoa, P. Prádanos, L. Palacio, A. Hernández, Morphology and structure of ABS membranes filled with two different activated carbons, Chemical Engineering Science, 61 (2006) 5448-5454.

[28] H.A. Daynes, The process of diffusion through a rubber membrane, in, Proc. R. Soc. London 97, London, 1920, pp. 286-307.

[29] J. Crank, The mathematics of diffusion, Clarendon Press, Oxford [England] :, 1975.

[30] D.R. Paul, A.T. DiBenedetto, Diffusion in amorphous polymers, Journal of Polymer Science Part C: Polymer Symposia, 10 (1965) 17-44.

[31] S.W. Rutherford, D.D. Do, Review of time lag permeation technique as a method for characterisation of porous media and membranes, Adsorption, 3 (1997) 283-312.

[32] J.L. Hedrick, K.R. Carter, H.J. Cha, C.J. Hawker, R.A. DiPietro, J.W. Labadie, R.D. Miller, T.P. Russell, M.I. Sanchez, W. Volksen, D.Y. Yoon, D. Mecerreyes, R. Jerome, J.E. McGrath, High-temperature polyimide nanofoams for microelectronic applications, Reactive and Functional Polymers, 30 (1996) 43-53.

[33] A. Marcos-Fernández, A. Tena, A.E. Lozano, J.G. de la Campa, J. de Abajo, L. Palacio, P. Prádanos, A. Hernández, Physical properties of films made of copoly(etherimide)s with long poly(ethylene oxide) segments, European Polymer Journal, 46 (2010) 2352-2364.

[34] S.-H. Hsiao, Y.-J. Chen, Structure-property study of polyimides derived from PMDA and BPDA dianhydrides with structurally different diamines, European Polymer Journal, 38 (2002) 815-828.

[35] D.W. Van Krevelen, Properties of polymers in: third edition, Elsevier, Amsterdam, 1990, pp. 120

[36] J. Brandrup, E.H. Immergut, E.A. Grulke, A. Abe, D.R. Bloch, Polymer Handbook (4th Edition), in, John Wiley \& Sons, 1999.

[37] A. Tena, A. Marcos-Fernández, L. Palacio, P. Cuadrado, P. Prádanos, J. de Abajo, A.E. Lozano, A. Hernández, Phase Segregation and Gas Separation Properties of Thermally Treated Copoly(ether-imide) from an Aromatic Dianhydride, an Aromatic Diamine, and Various Aliphatic Diamines, Industrial \& Engineering Chemistry Research, 51 (2012) 3766-3775.

[38] L.M. Robeson, Correlation of separation factor versus permeability for polymeric membranes, Journal of Membrane Science, 62 (1991) 165-185.

[39] L.M. Robeson, The upper bound revisited, Journal of Membrane Science, 320 (2008) 390-400.

[40] K. Tanaka, H. Kita, M. Okano, K.I. Okamoto, Permeability and permselectivity of gases in fluorinated and non-fluorinated polyimides, Polymer, 33 (1992) 585-592.

[41] C.E. Powell, G.G. Qiao, Polymeric $\mathrm{CO}_{2} / \mathrm{N}_{2}$ gas separation membranes for the capture of carbon dioxide from power plant flue gases, Journal of Membrane Science, 279 (2006) 1-49.

[42] J.C. Maxwell, A treatise on electricity and magnetism, in: vol. 1, Dover Publications Inc, New York, 1954. 


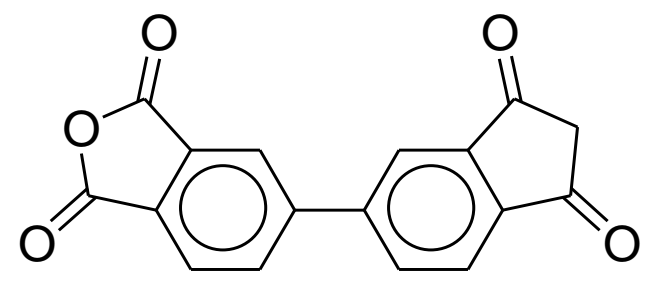

BPDA

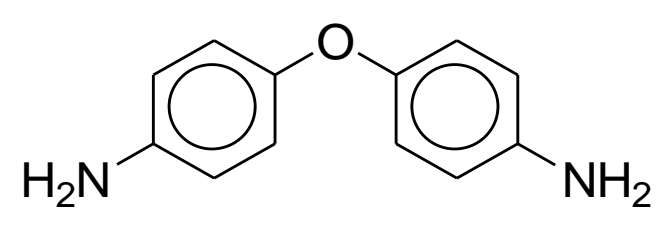

ODA<smiles>CC(N)COCCOCC(C)N</smiles>

PEO-2000
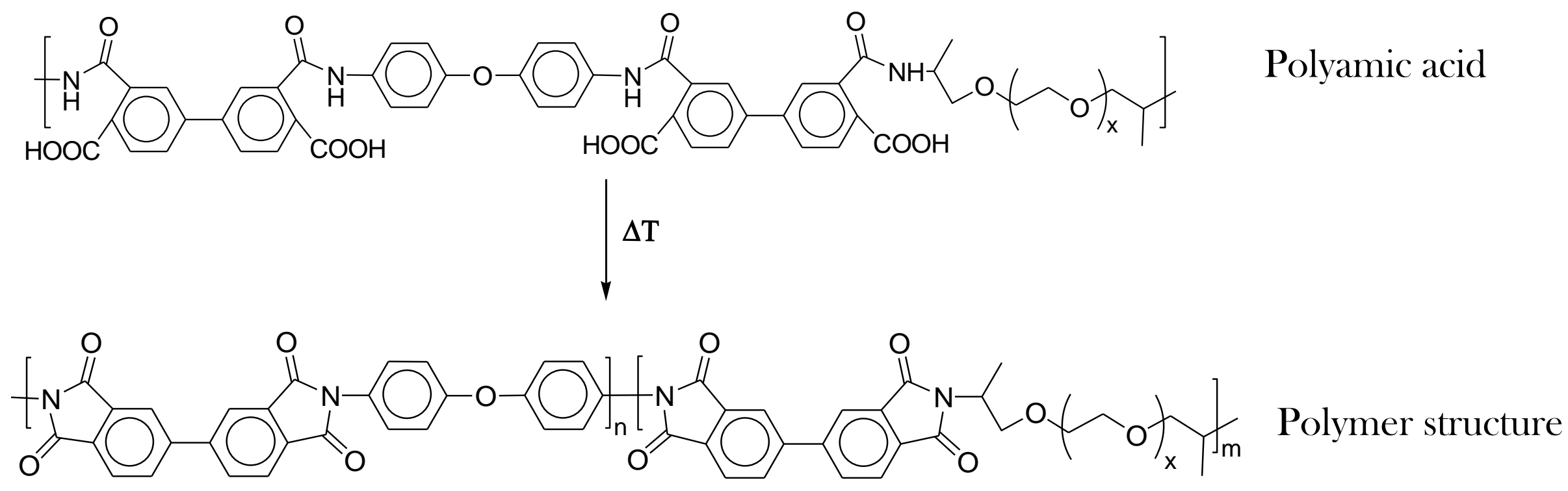

Figure 1. Chemical structure of the monomers and reaction process 


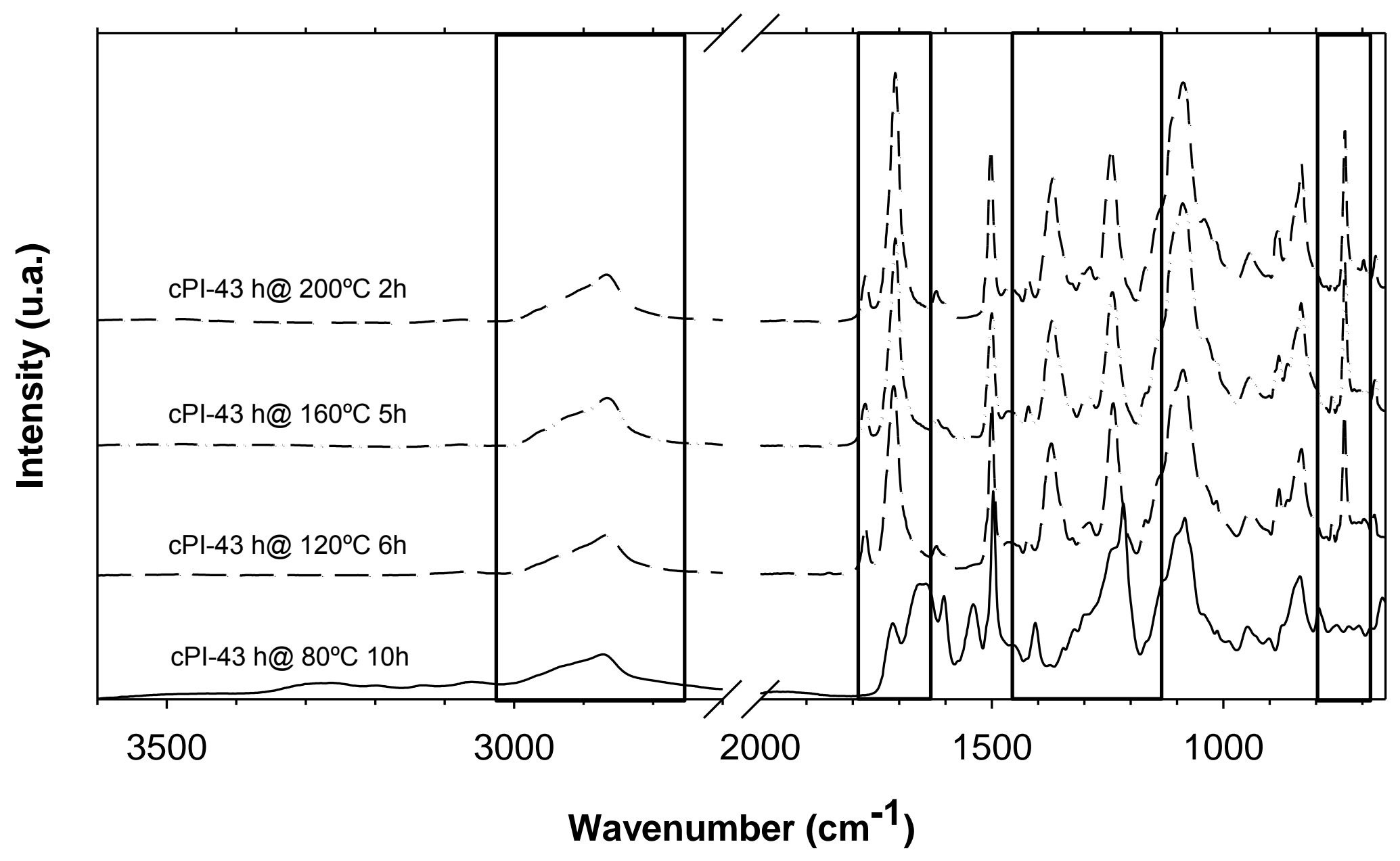

Figure 2. FTIR spectra of copolymer $\mathrm{cPI}-43$ before imidization $\left(80^{\circ} \mathrm{C}\right)$ and after the thermal treatment at different temperatures $\left(120,160\right.$ and $\left.200^{\circ} \mathrm{C}\right)$. 


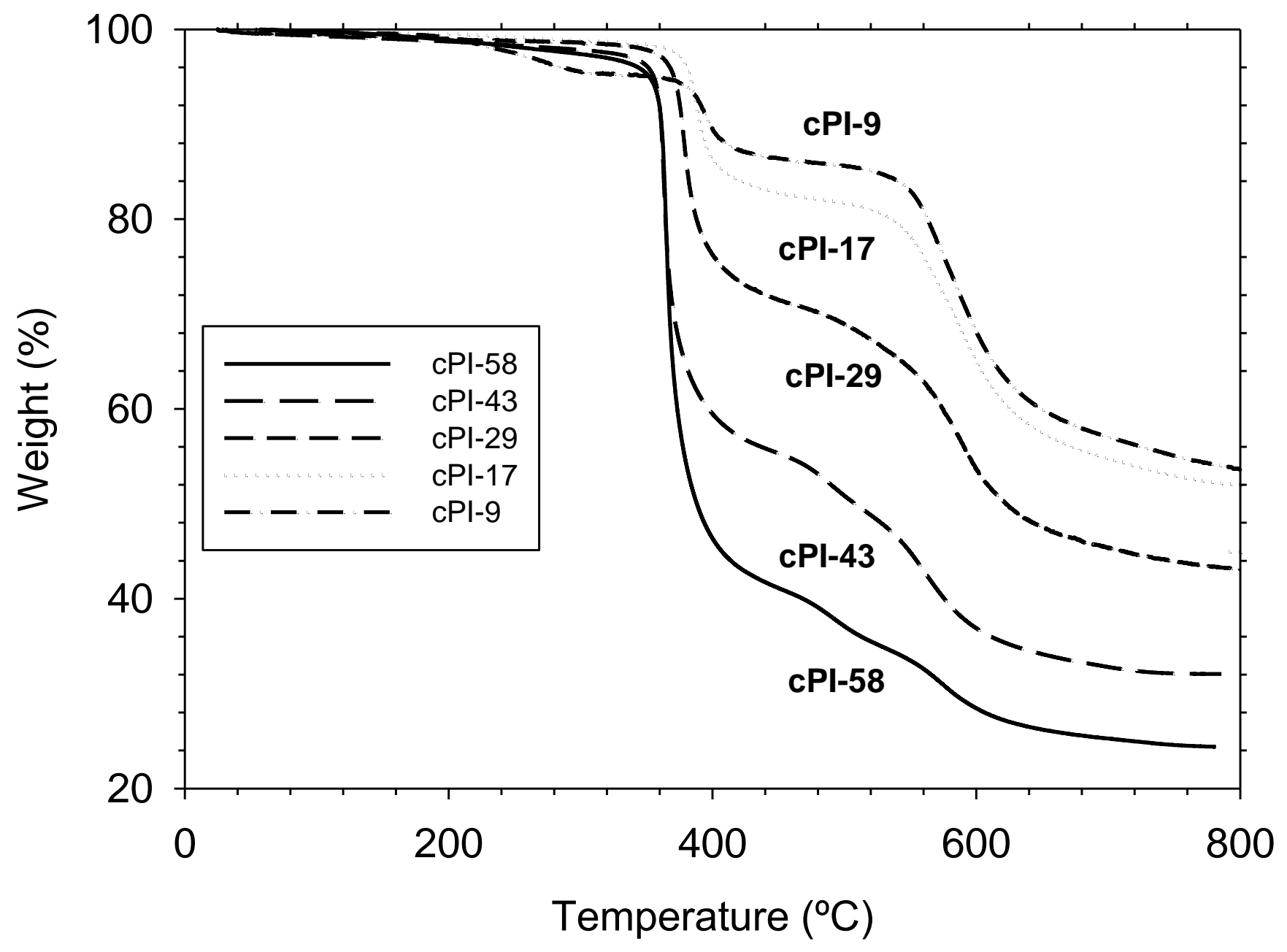

Figure 3. TGA curves in dynamic conditions for PEO based copolymers. From top to bottom: cPI-9 (treated at $180{ }^{\circ} \mathrm{C}$ for 6 hours); $\mathrm{cPI}-17$ (treated at $180{ }^{\circ} \mathrm{C}$ for 6 hours); cPI29 (treated at $160{ }^{\circ} \mathrm{C}$ for 6 hours); CPI-43 and cPI-58 (treated at $120{ }^{\circ} \mathrm{C}$ for 6 hours). 


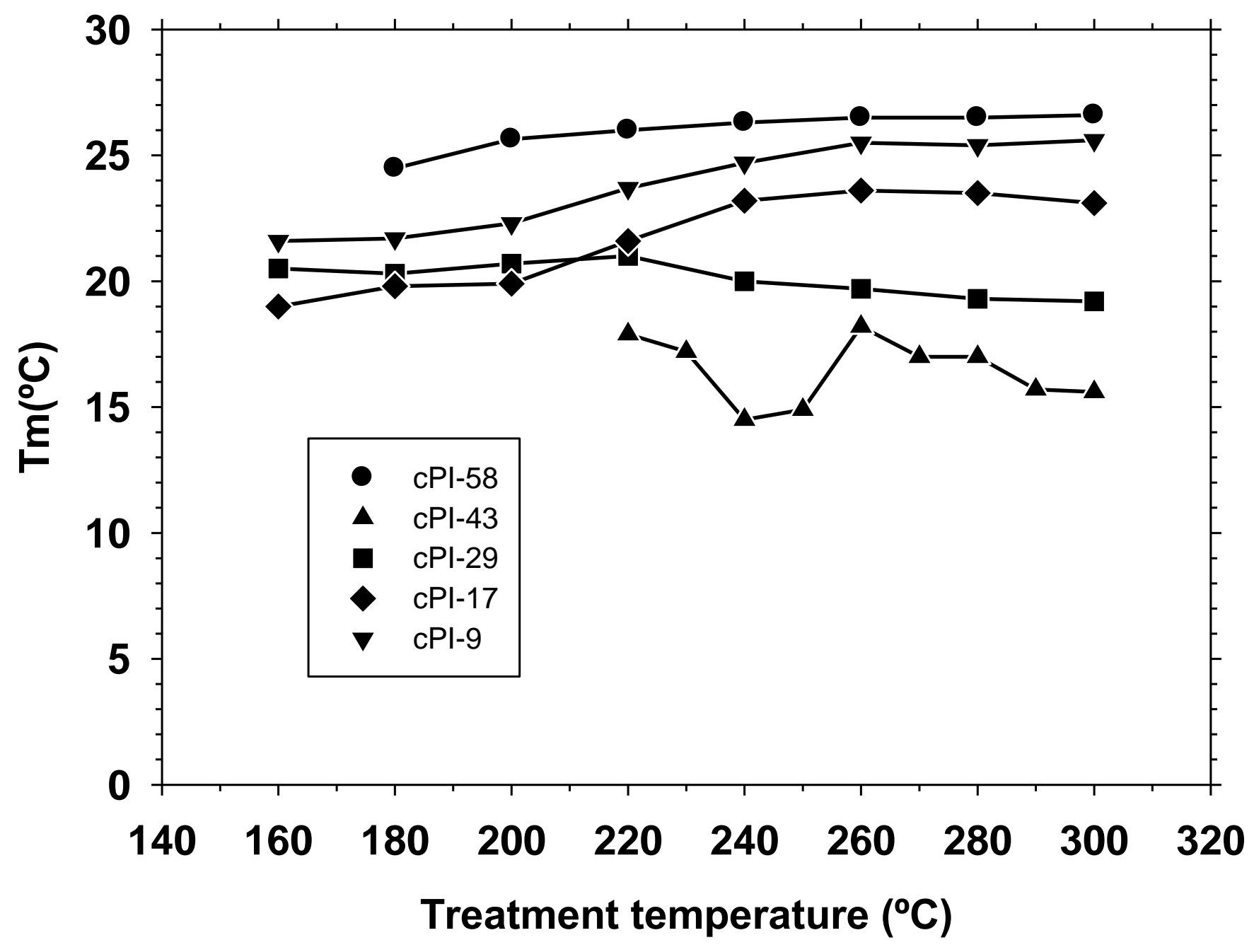

Figure 4. Melting temperatures as a function of the treatment temperature. 

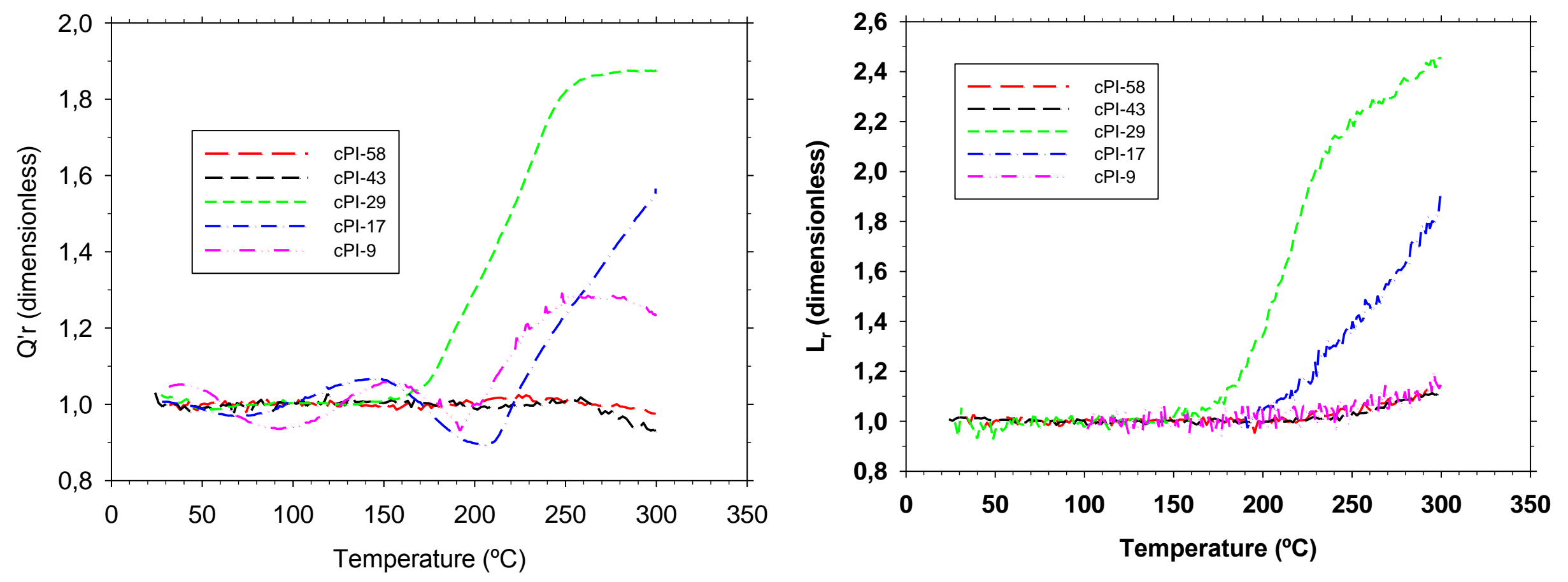

Figure 5. Evolution of $Q_{r}^{\prime}$ and $L_{r}$ as a function of temperature of treatment. 


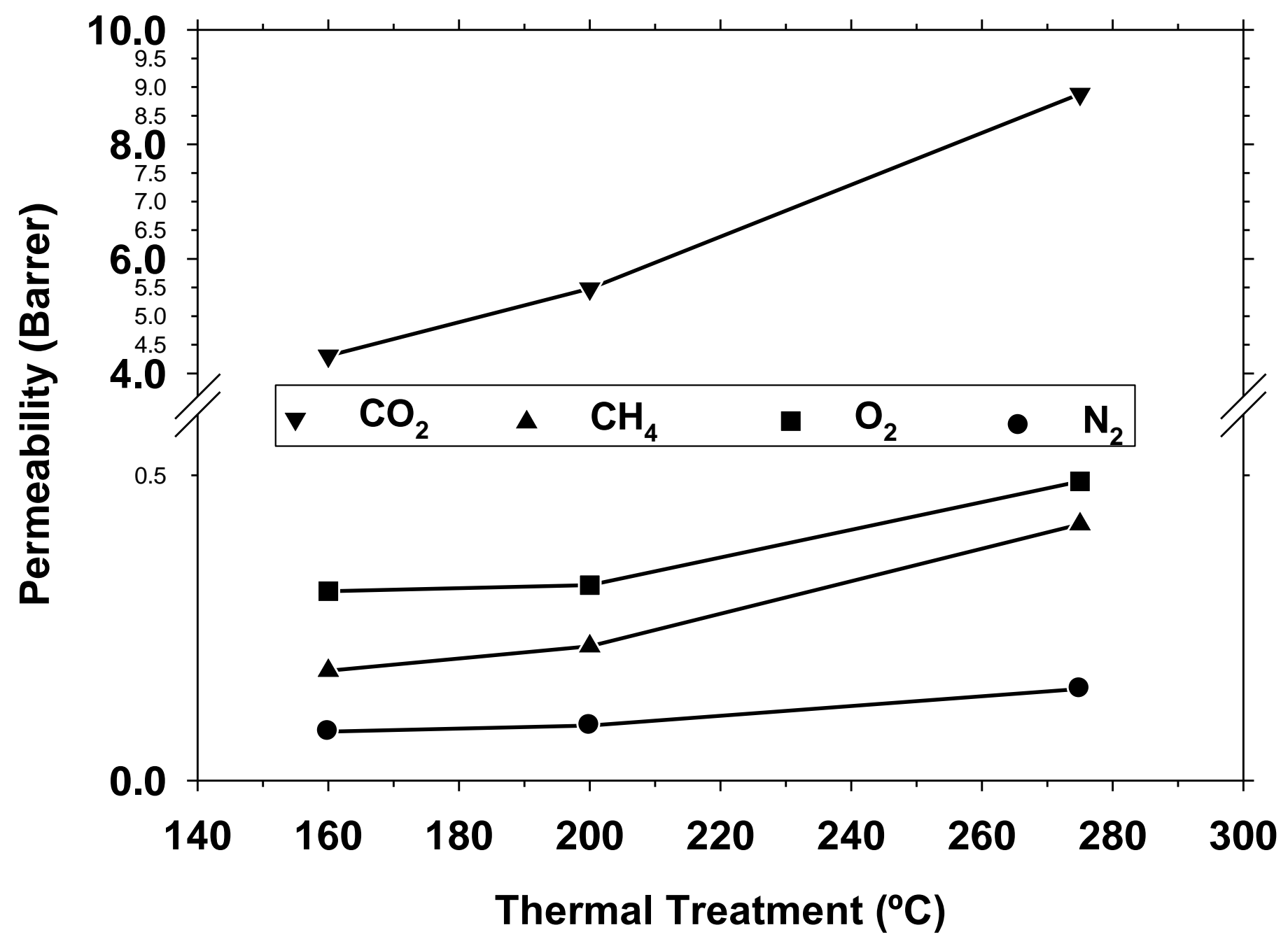

Figure 6 . Permeability versus treatment temperature for the copolymer cPI-29. 


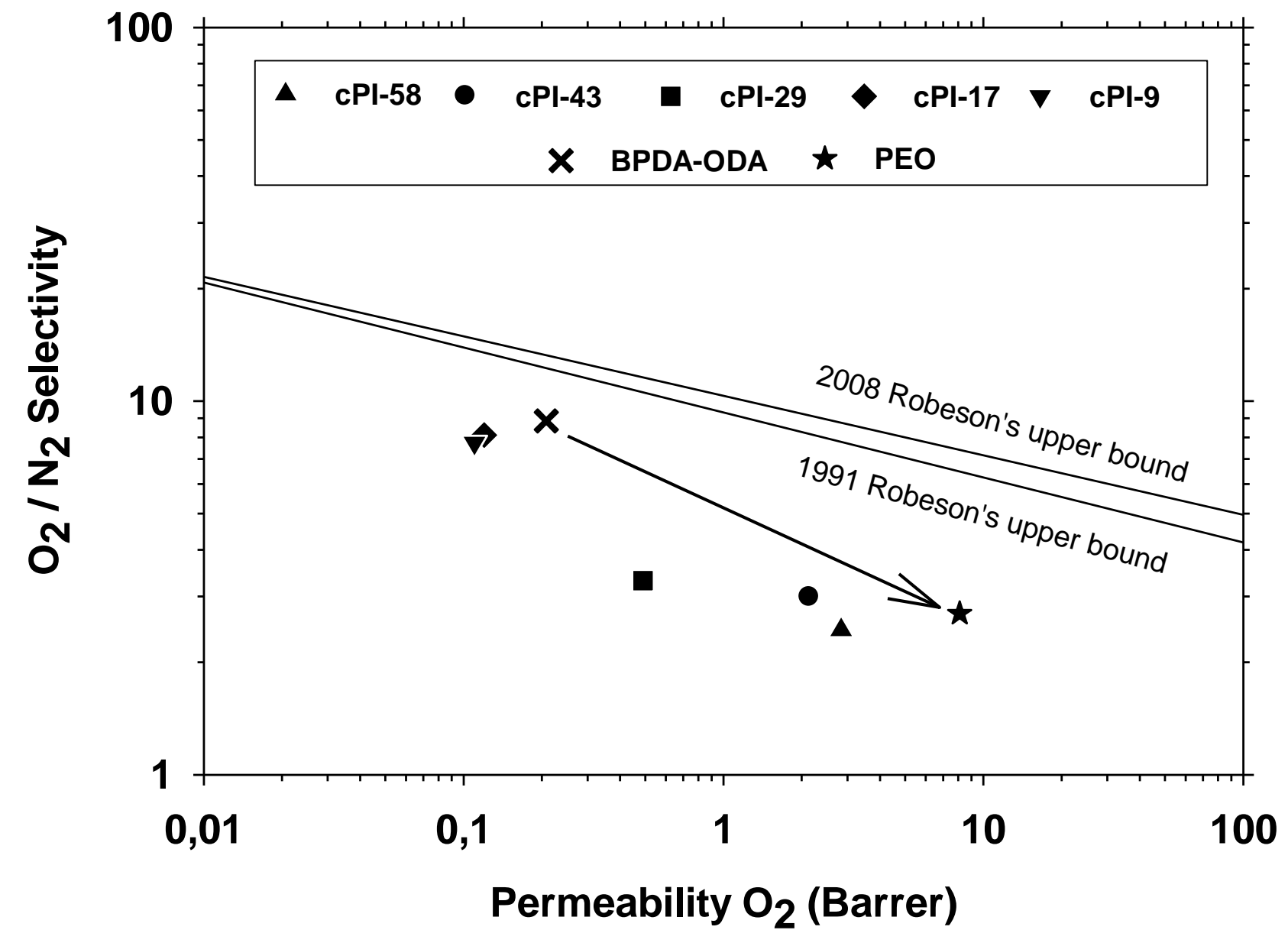

Figure 7. Robeson's plot for the $\mathrm{O}_{2} / \mathrm{N}_{2}$ gas pair. The cross corresponds to BPDA-ODA and the star to PEO (at $275^{\circ} \mathrm{C}$ for $\mathrm{cPI}-9, \mathrm{cPI}-17$ and $\mathrm{cPI}-29$, and $250 \stackrel{\circ}{ } \mathrm{C}$ for $\mathrm{cPI}-43$ and cPI-58) 


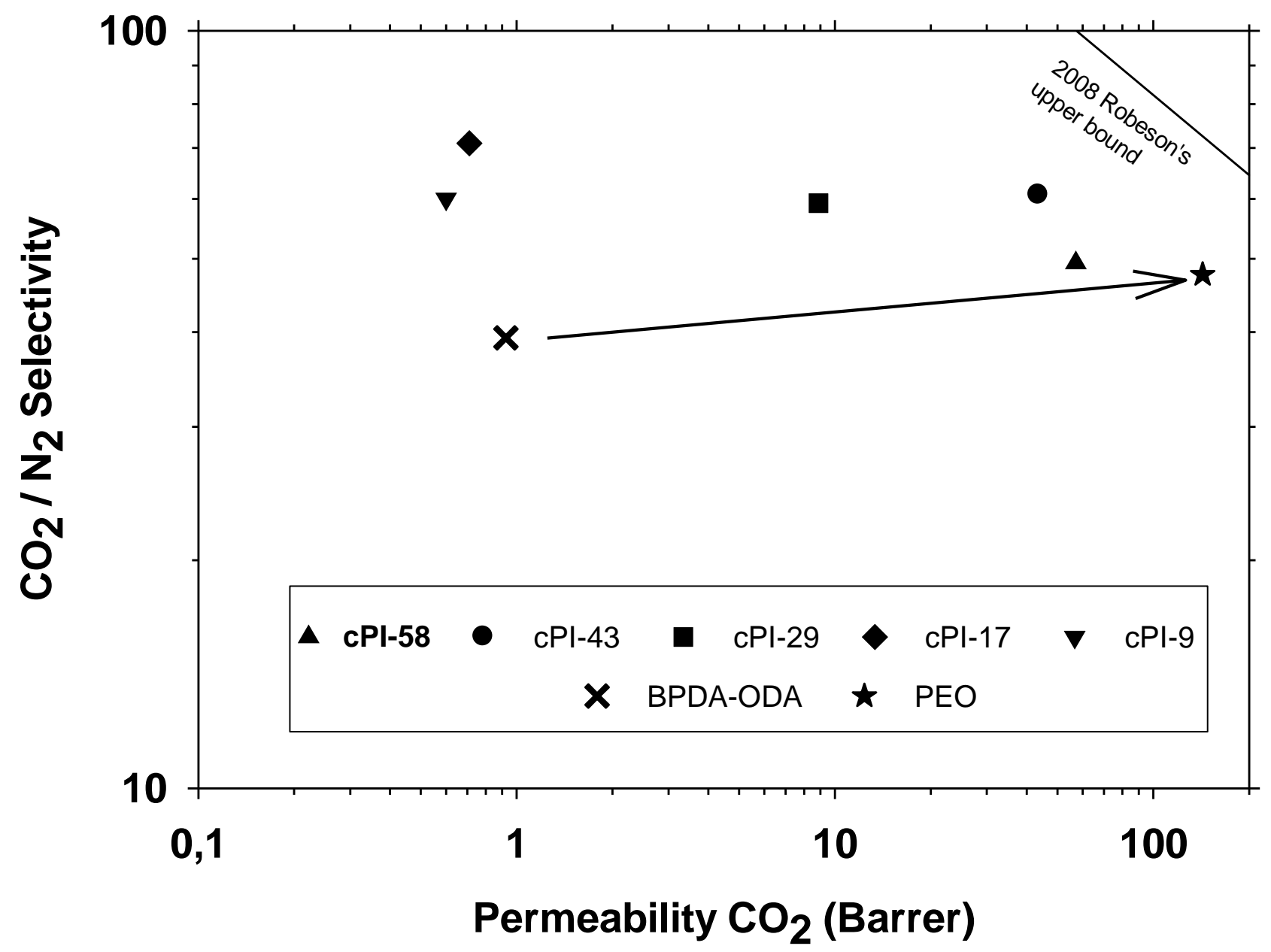

Figure 8. Robeson's plot for the $\mathrm{CO}_{2} / \mathrm{N}_{2}$ gas pair. The cross corresponds to BPDA-ODA and the star to PEO (at $275^{\circ} \mathrm{C}$ for $\mathrm{CPI}-9, \mathrm{cPl}-17$ and $\mathrm{cPI}-29$, and $250{ }^{\circ} \mathrm{C}$ for $\mathrm{cPl}-43$ and cPI-58) 


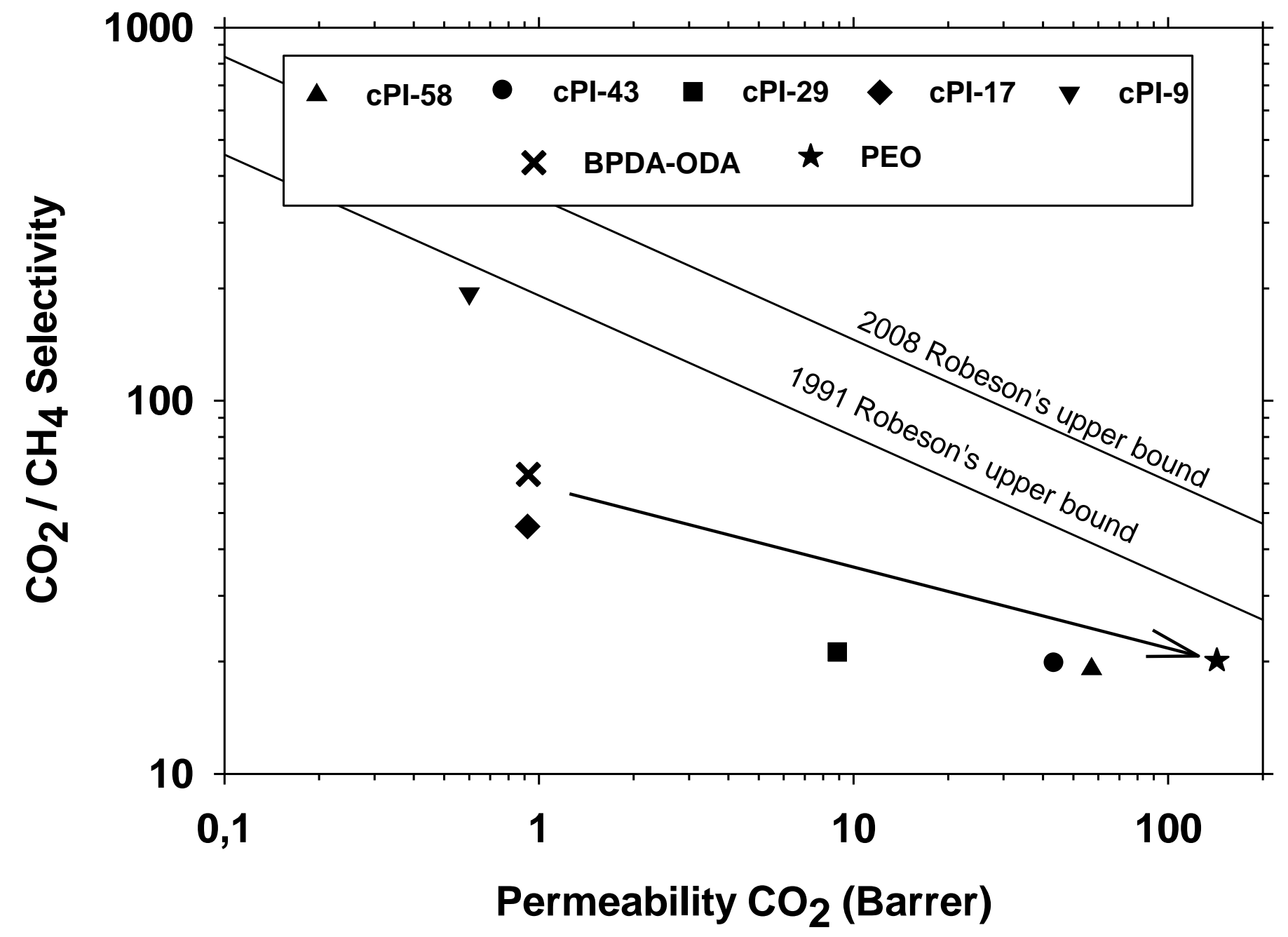

Figure 9. Robeson's plot for the $\mathrm{CO}_{2} / \mathrm{CH}_{4}$ gas pair. The cross corresponds to BPDA$\mathrm{ODA}$ and the star to PEO (at $275{ }^{\circ} \mathrm{C}$ for $\mathrm{cPI}-9, \mathrm{cPI}-17$ and $\mathrm{cPI}-29$, and $250 \stackrel{\circ}{\circ} \mathrm{C}$ for $\mathrm{cPI}-43$ and $\mathrm{CPI}-58)$ 


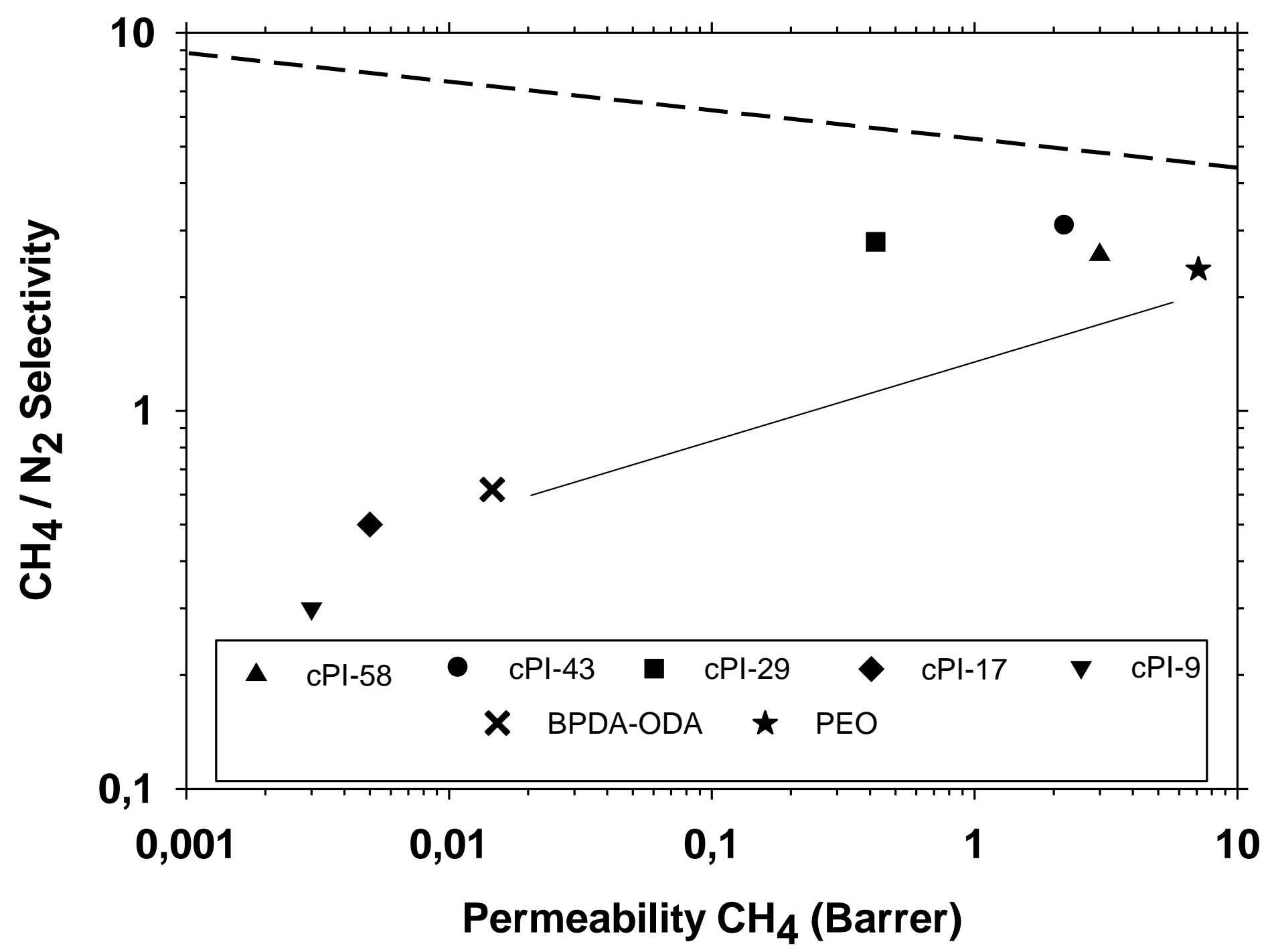

Figure 10. Robeson's plot for the $\mathrm{CH}_{4} / \mathrm{N}_{2}$ gas pair. The cross corresponds to BPDA-ODA and the star to PEO (at $275^{\circ} \mathrm{C}$ for $\mathrm{CPI}-9, \mathrm{cPI}-17$ and $\mathrm{cPI}-29$, and $25{ }^{\circ} \mathrm{C}$ for $\mathrm{CPI}-43$ and cPI-58) 


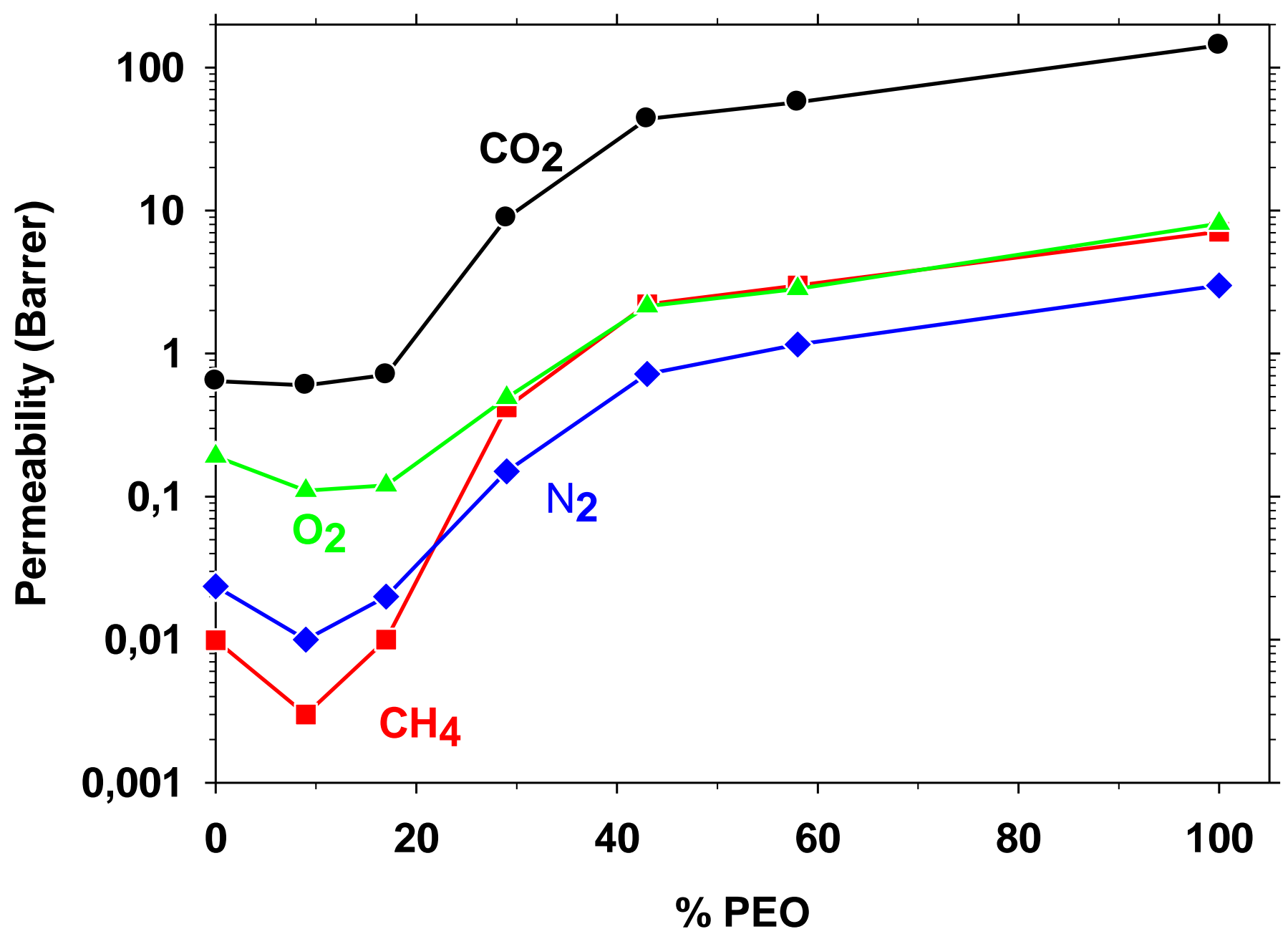

Figure 11 . Permeability as a function of the percentage of PEO (at $275^{\circ} \mathrm{C}$ for $\mathrm{cPI}-9$, cPI17 and $\mathrm{cPI}-29$, and $250^{\circ} \mathrm{C}$ for $\mathrm{cPI}-43$ and $\mathrm{cPI}-58$ ) 


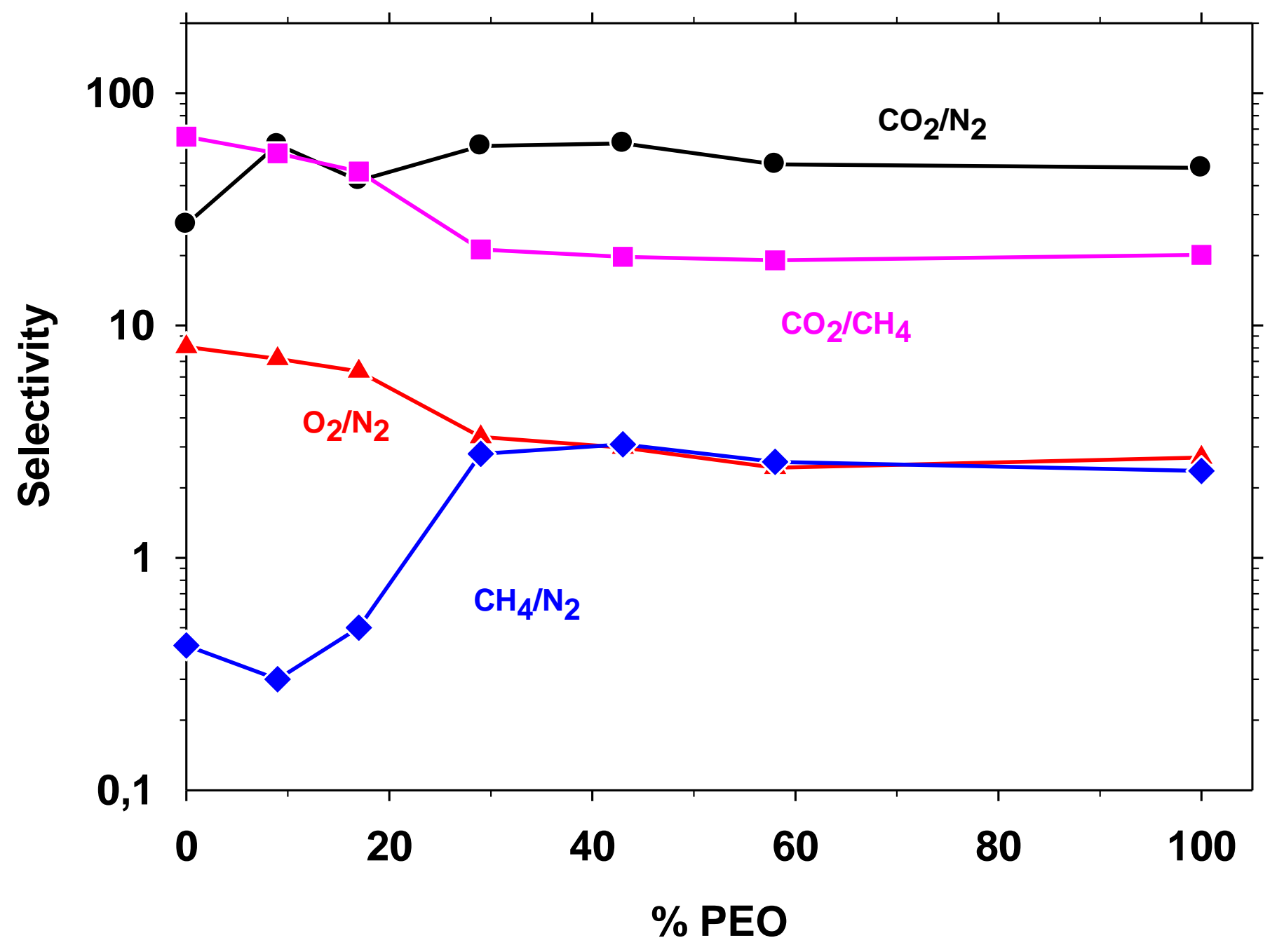

Figure 12. Selectivity variation as a function of percent of PEO (at $275^{\circ} \mathrm{C}$ for $\mathrm{cPI}-9$, $\mathrm{cPI}-17$ and $\mathrm{cPI}-29$, and $250^{\circ} \mathrm{C}$ for $\mathrm{cPI}-43$ and $\mathrm{cPI}-58$ ) 


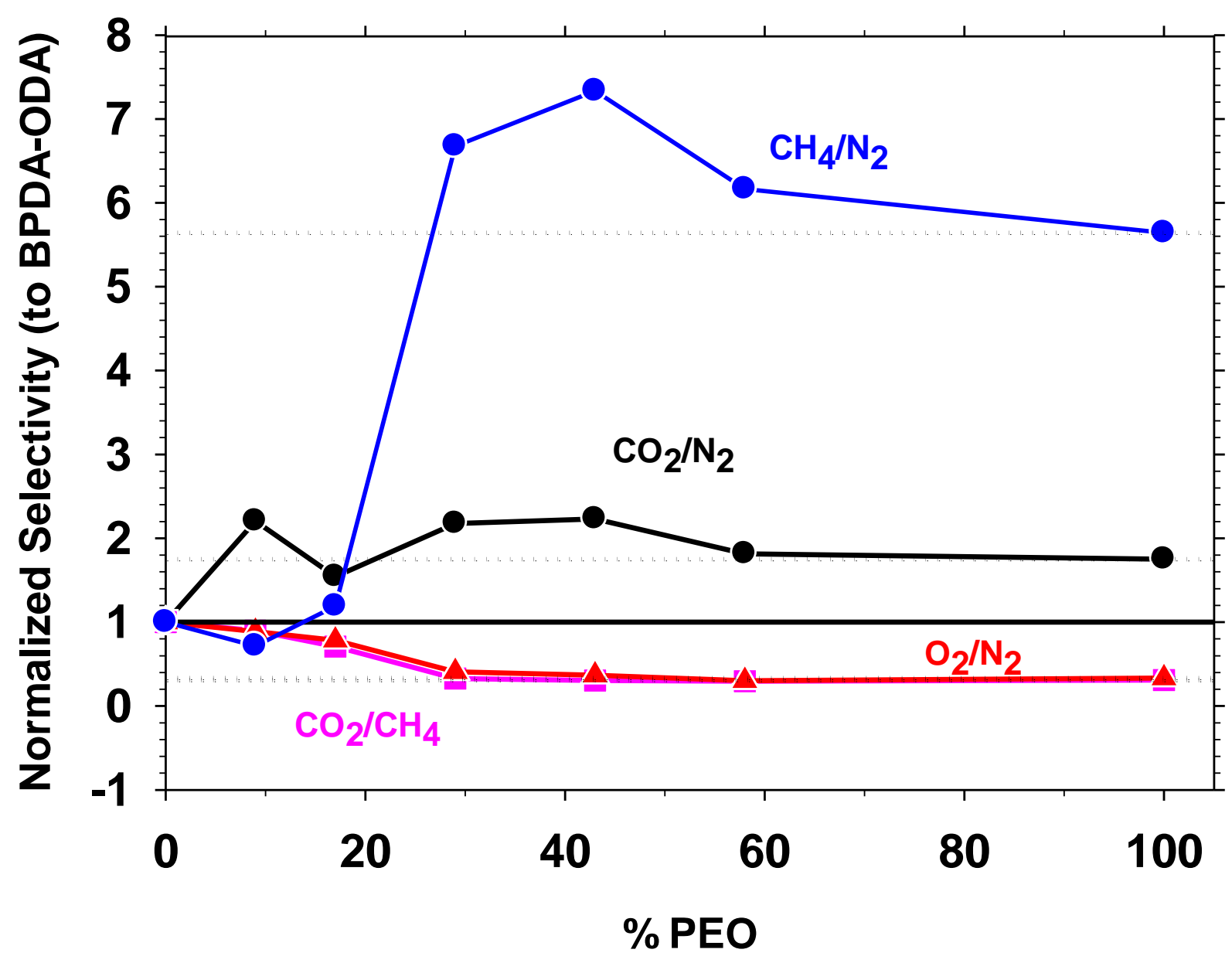

Figure 13. Selectivity distance from BPDA-ODA selectivity values as a function of the proportion of PEO (at $275^{\circ} \mathrm{C}$ for $\mathrm{cPI}-9, \mathrm{cPl}-17$ and $\mathrm{cPI}-29$, and $250{ }^{\circ} \mathrm{C}$ for $\mathrm{CPI}-43$ and cPI-58) 

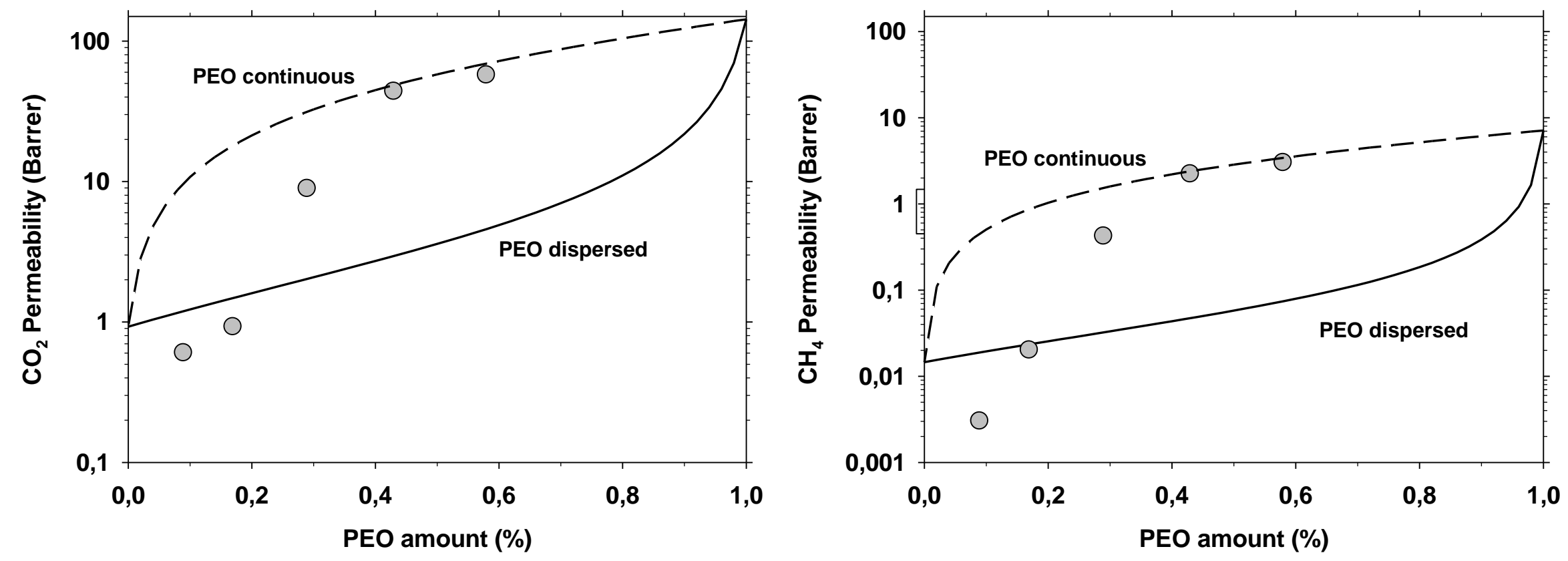

Figure 14. Predicted values for $\mathrm{CO}_{2}$ (a) and $\mathrm{CH}_{4}$ (b) using Maxwell equation comparing with the experimental for the samples at maximum treatment temperature (at $275{ }^{\circ} \mathrm{C}$ for $\mathrm{cPI}-9$, cPI-17 and cPI-29, and $250{ }^{\circ} \mathrm{C}$ for $\mathrm{cPI}-43$ and cPI-58 

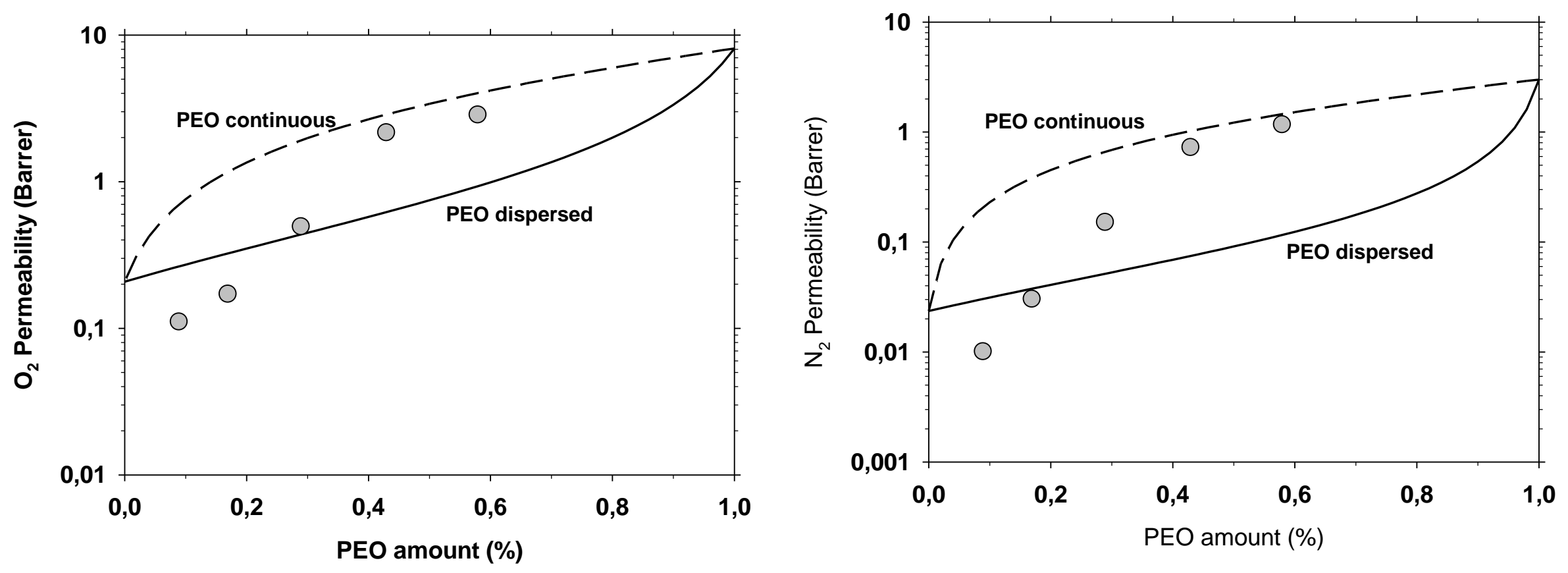

Figure 15a. Predicted values for $\mathrm{O}_{2}$ using Maxwell equation comparing with the experimental for the samples at maximum treatment temperature (at $275 \stackrel{\circ}{\circ} \mathrm{C}$ for $\mathrm{cPI}-9$, $\mathrm{cPI}-17$ and $\mathrm{cPI}-29$, and $250{ }^{\circ} \mathrm{C}$ for $\mathrm{cPI}-43$ and $\mathrm{cPI}-58$ 
Table 1. Polymers synthesized in this work.

\begin{tabular}{|c|c|c|c|}
\hline Sample & Acronym & Weight ratio PEO/ODA & $\begin{array}{c}\text { Imidization Temperature } \\
\text { ( }\end{array}$ \\
\hline BPDA PEO2000 ODA 4_1 & cPI-58 & $4: 1$ & 120 \\
\hline BPDA PEO2000 ODA 2_1 & cPI-43 & $2: 1$ & 120 \\
\hline BPDA PEO2000 ODA 1_1 & cPI-29 & $1: 1$ & 180 \\
\hline BPDA PEO2000 ODA 1_2 & cPI-17 & $1: 2$ & 180 \\
\hline BPDA PEO2000 ODA 1_4 & cPI-9 & $1: 4$ & \\
\hline
\end{tabular}

Table 2. Results obtained by TGA for the prepared copolymers. The residue of the BPDA-ODA homopolymer at $800^{\circ} \mathrm{C}$ is $64 \%$ [34].

\begin{tabular}{|c|c|c|c|c|}
\hline Copolymer & $\begin{array}{l}\text { Theoretical } \\
\text { polyether } \\
\text { weight in the } \\
\text { copolymer (\%) }\end{array}$ & $\begin{array}{l}\text { Experimental } \\
\text { polyether } \\
\text { weight loss (\%) }\end{array}$ & $\begin{array}{l}\text { Temperature } \\
\text { of maximum } \\
\text { weight loss } \\
\text { rate / }{ }^{\circ} \mathbf{C}\end{array}$ & $\begin{array}{l}\text { Residue } \\
\text { at } 800^{\circ} \mathrm{C} / \\
\%\end{array}$ \\
\hline CPI-58 & 58.5 & 58.2 & 365 & 24.9 \\
\hline cPI-43 & 43.7 & 43.6 & 363 & 34.9 \\
\hline CPI-29 & 29.2 & 25.6 & 377 & 46.7 \\
\hline CPI-17 & 17.5 & 16.2 & 382 & 52.6 \\
\hline CPI-9 & 9.7 & 9.1 & 394 & 56.1 \\
\hline
\end{tabular}

